ARTICLE

\title{
The barley immune receptor Mla recognizes multiple pathogens and contributes to host range dynamics
}

Jan Bettgenhaeuser (10 1,6,11, Inmaculada Hernández-Pinzón (1D 1,11 , Andrew M. Dawson', Matthew Gardiner', Phon Green (1) 1, Jodie Taylor', Matthew Smoker ${ }^{1}$, John N. Ferguson 1,7, Peter Emmrich 1,8, Amelia Hubbard ${ }^{2}$, Rosemary Bayles², Robbie Waugh (10 3, Brian J. Steffenson (10 4 , Brande B. H. Wulff (1) 1,9, Antonín Dreiseitl (1) ${ }^{5}$, Eric R. Ward ${ }^{1,10} \&$ Matthew J. Moscou (i) ${ }^{1 凶}$

Crop losses caused by plant pathogens are a primary threat to stable food production. Stripe rust (Puccinia striiformis) is a fungal pathogen of cereal crops that causes significant, persistent yield loss. Stripe rust exhibits host species specificity, with lineages that have adapted to infect wheat and barley. While wheat stripe rust and barley stripe rust are commonly restricted to their corresponding hosts, the genes underlying this host specificity remain unknown. Here, we show that three resistance genes, Rps6, Rps7, and Rps8, contribute to immunity in barley to wheat stripe rust. Rps7 cosegregates with barley powdery mildew resistance at the Mla locus. Using transgenic complementation of different Mla alleles, we confirm allele-specific recognition of wheat stripe rust by Mla. Our results show that major resistance genes contribute to the host species specificity of wheat stripe rust on barley and that a shared genetic architecture underlies resistance to the adapted pathogen barley powdery mildew and non-adapted pathogen wheat stripe rust.

\footnotetext{
${ }^{1}$ The Sainsbury Laboratory, University of East Anglia, Norwich Research Park, Norwich NR4 7UK England, UK. ${ }^{2}$ NIAB, 93 Lawrence Weaver Road, Cambridge CB3 OLE England, UK. ${ }^{3}$ The James Hutton Institute, Invergowrie, Dundee DD2 5DA Scotland, UK. ${ }^{4}$ Department of Plant Pathology, University of Minnesota, St. Paul, MN 55108, USA. ${ }^{5}$ Department of Integrated Plant Protection, Agrotest Fyto Ltd, Havlíčkova 2787, CZ-767 01 Kroměříž, Czech Republic. ${ }^{6}$ Present address: KWS SAAT SE \& Co. KGaA, 37574 Einbeck, Germany. ${ }^{7}$ Present address: Department of Plant Sciences, University of Cambridge, Downing Street, Cambridge CB2 3EA, UK. ${ }^{8}$ Present address: John Innes Centre, Norwich Research Park, Norwich NR4 7UH, UK. ${ }^{9}$ Present address: Center for Desert Agriculture, Biological and Environmental Science and Engineering Division (BESE), King Abdullah University of Science and Technology, Thuwal 239556900, Saudi Arabia. ${ }^{10}$ Present address: AgBiome, Research Triangle Park, NC 27709, USA. ${ }^{11}$ These authors contributed equally: Jan Bettgenhaeuser, Inmaculada Hernández-Pinzón. ${ }^{凶}$ email: matthew.moscou@tsl.ac.uk
} 
$\mathrm{P}$ lants are constantly exposed to a diverse array of pathogens, but remain resistant to the vast majority of microbial invaders $^{1}$. This phenomenon is termed nonhost resistance ${ }^{2}$ and collectively refers to the interaction of plants with nonadapted pathogens. Early work by Eriksson ${ }^{3}$ in 1894 found that Puccinia striiformis (stripe rust) only infected Triticeae species from which they were originally isolated. This host species specificity appeared to be common among diverse rust pathogens of grasses. These specialized forms, designated formae speciales, were later observed in several filamentous pathogen systems, such as the powdery mildews of cereals (Blumeria graminis) ${ }^{4}$ and smuts (Ustilago spp. $)^{5}$ on the Triticeae, vascular wilt caused by Fusarium oxysporum ${ }^{6}$, blast (Magnaporthe spp.) of grasses ${ }^{7}$, the downy mildews (Bremia spp.) of Asteraceae ${ }^{8}$, and white rusts (Albugo spp.) of Brassiceae ${ }^{9}$. From these early observations of host adapted lineages in diverse plant-pathogen systems, considerable progress has been made in understanding the genetic architecture underlying resistance to non-adapted pathogens. One of the earliest approaches to discover the genetic basis of non-adapted resistance of rye (Secale cereale L.) involved the cytogenetic transfer of individual chromosomes to wheat (Triticum aestivum L.) ${ }^{10}$. Using interspecific crosses, Riley and Macer found that individual chromosomes from rye conferred resistance to wheat powdery mildew and wheat stripe rust. This work established that resistance to non-adapted pathogens in closely related species is genetically simple, likely determined by individual loci. Subsequent work using crosses of different formae speciales of $B$. graminis found that four resistance genes and avirulence genes conditioned the formae speciales divide between wheat and Agropyron and their corresponding powdery mildews ${ }^{11}$. While several genetic loci have been defined, it is unclear whether the resistance conditioned at these loci is distinct or overlapping with resistance to host pathogens.

The plant immune system is composed of successive layers of passive and active barriers that provide resistance to pathogens ${ }^{12}$. Passive barriers include the cuticle and cell wall, whereas active barriers include reactive oxygen species, secondary metabolites with antimicrobial activity, lignification of the cell wall, callose deposition, and cell death. Recognition of pathogens is mediated by membrane-bound and intracellular immune receptors, which serve to recognize pathogen-derived molecules and perceive danger signals ${ }^{13,14}$. Membrane-bound immune receptors (pattern recognition receptors) are structurally composed of a variable extracellular, ligand-binding domain, transmembrane domain or glycophosphatidylinositol (GPI) anchor, and a variable intracellular protein kinase domain ${ }^{15}$. The largest class of intracellular immune receptors in land plants are the nucleotide bindingleucine rich repeat (NLR) proteins ${ }^{16}$. Pathogens have evolved several mechanisms to overcome plant immunity. These include the use of enzymatic degradation and mechanical turgor to breach the cell wall ${ }^{17}$, apoplastically secreted proteins that sequester fungal cell wall fragments that would elicit immune responses $^{18}$, and proteinacious and non-proteinacious effectors that are secreted into the plant cell to suppress immunity and facilitate nutrient acquisition ${ }^{19}$.

NLR encoding loci are highly complex, exhibiting substantial copy number variation, structural rearrangements, and novel gene content between allelic variants ${ }^{20}$. Recognition of plant pathogens by NLR occurs through direct or indirect recognition of effectors ${ }^{21}$. Direct recognition occurs through a physical interaction of NLR and effector, whereas indirect recognition occurs through the monitoring of a host protein by an NLR. Upon modification of the host protein, the NLR initiates an immune response that leads to resistance. The mechanism underlying indirect recognition, i.e. guarding of host proteins by NLRs, suggests that multiple pathogens could be recognized if their effectors target a conserved host protein. Of the hundreds of described NLRs conferring resistance to plant pathogens, only a few NLRs have been shown to natively recognize taxonomically distant pathogens: RPS4/RRS122-25 and $M i^{26,27}$. The observed low frequency of NLRs that recognize multiple pathogens can be explained by several factors. It may be that NLRs are extremely specific in their interaction with host proteins such that they have the capacity to only recognize a specific modification or alternatively, an insufficient number of plant-pathogen systems have been investigated to establish the broader capacity for NLR recognition.

The Mla (Mildew locus a) locus ${ }^{28}$ in barley (Hordeum vulgare) exhibits extensive structural and copy number variation, and is known to contain three different NLR encoding gene families (RGH1, RGH2, and RGH3) ${ }^{29-32}$. Within the locus, resistance to barley powdery mildew (B. graminis f. sp. hordei; Bgh) is conferred by members of the RGH1 gene family. Mla has over 30 characterized alleles with different specificities for recognition of barley powdery mildew ${ }^{33,34}$. In closely related cereals such as rye (Secale cereale), the Mla homolog Sr50 confers resistance to wheat stem rust (Puccinia graminis f. sp. tritici) ${ }^{35}$, whereas TmMla1 ${ }^{36}$ and $\mathrm{Sr}_{3} 3^{37}$ in Triticum monococcum and Aegilops tauschii (wheat D-genome progenitor) confer resistance to wheat powdery mildew (B. graminis f. sp. tritici) and wheat stem rust (P. graminis $\mathrm{f}$. sp. tritici), respectively. Several effectors recognized by the Mla $(R G H 1)$ gene family have been identified ${ }^{38-40}$. All of these are predicted small (102-132 aa) secreted peptides with divergent sequence composition, with the exception of the allelic variants $\mathrm{AVR}_{\mathrm{a} 10}$ and $\mathrm{AVR}_{\mathrm{a} 22}{ }^{40}$. Thus, Mla homologs recognize effectors from ascomycete and basidiomycete pathogens.

Stripe rust (yellow rust; $P$. striiformis) is a filamentous fungal pathogen of the Triticeae, causing substantial global yield loss, particularly in wheat ${ }^{41}$. After landing on a leaf, $P$. striiformis generates a germ tube, invades via stomata, and initiates the infection process through hyphal colonization, followed by a transition to pustule formation (reproduction). Wheat stripe rust (P. striiformis f. sp. tritici, Pst) and barley stripe rust (P. striiformis f. sp. hordei, Psh) exhibit host species specificity to wheat and barley. We set out to understand the genetic architecture underlying resistance to wheat stripe rust in barley (Hordeum vulgare). Previous work suggests that host species specificity to stripe rust is conditioned by resistance genes ${ }^{42-46}$, but the complexity and diversity of these genes in a range of germplasm, their identity, and the impact of domestication and plant breeding on their prevalence remain unclear. In this study, we interrogate a representative panel of barley accessions for their reaction to this non-adapted pathogen and found three loci, Rps6, Rps7, and $R p s 8$, which determine host species specificity in barley at different stages of the pathogen lifecycle. These loci are present across the range of barley diversity including wild, landrace, and elite accessions and form the basis of a wheat stripe rust resistance gene complex in barley. Rps 7 is mapped to the barley powdery mildew resistance locus, Mla. Based on high-resolution recombination screens and transgenic complementation we show that different alleles of $\mathrm{Mla}$ confer resistance to barley powdery mildew and wheat stripe rust.

\section{Results}

Wild barley exhibits extensive phenotypic diversity to Pst isolate $08 / 21$ compared to domesticated barley. We started our investigation of the genetic architecture of resistance to wheat stripe rust in barley by screening the reaction to Pst isolate $08 / 21$ in a diverse collection of barley germplasm, which included 76 cultivars, 20 landraces, and 27 wild accessions (Supplementary Data 1$)^{47}$. The genetic diversity of the panel was assessed by 

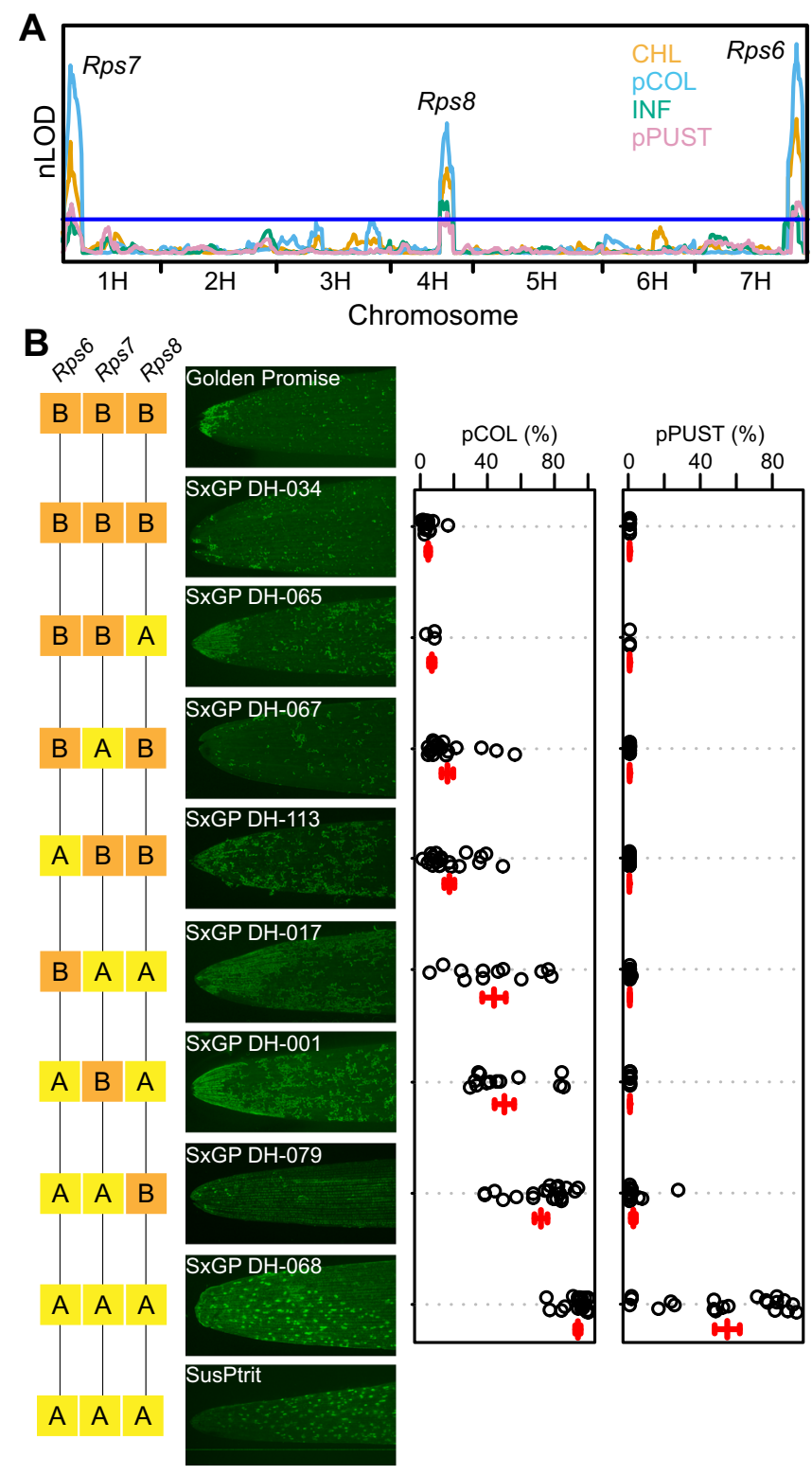

Fig. 1 Three loci underpin resistance to wheat stripe rust (P. striiformis $f$. sp. tritici) isolate 08/21 in Golden Promise. A Composite interval mapping of the SusPtrit $\times$ Golden Promise (SxGP) doubled-haploid (DH) population scored 14 days post-inoculation with $P$. striiformis $\mathrm{f}$. sp. tritici isolate $08 / 21$ using an additive model $\left(\mathrm{H}_{0}: \mathrm{H}_{1}\right)$. Phenotypes include macroscopic chlorosis $(\mathrm{CHL})$ and infection (i.e. pustule formation; INF) and microscopic hyphal colonization (pCOL) and pustule formation (pPUST). Results were plotted using normalized permutation thresholds ( $\mathrm{LLOD}$ ) with a threshold of statistical significance based on 1,000 permutations (blue horizontal line). B Three-way phenotype $\times$ genotype plots for $\mathrm{PCOL}$ and PPUST show the contribution of Rps6, Rps7, and Rps8 to resistance to P. striiformis f. sp. tritici isolate $08 / 21$ in the SxGP DH population. Error bars are mean and standard deviation for each genotypic group. 'A' and 'B' denote SusPtrit and Golden Promise alleles for each of the lines according to markers SCRI_RS_155652, BOPA2_12_30817, and BOPA1_4361-1867 for Rps6, Rps7, and Rps8, respectively. Micrographs are SxGP DH representative lines stained with WGA-FITC. Accessions and individuals per haplotype group: DH-034 $(N=13), \mathrm{DH}-065(N=3), \mathrm{DH}-067(N=18), \mathrm{DH}-113(N=20), \mathrm{DH}-017$ $(N=12), \mathrm{DH}-001(N=13), \mathrm{DH}-079(N=20)$, and $\mathrm{DH}-068(N=21)$. Data shown are one of two replicates based on $122 \mathrm{DH}$ lines, the same QTLS were identified in replicate experiments. Source data are provided as a Source Data file. genotyping 129 accessions with $1,536 \mathrm{SNPs}^{48}$. A total of 1,258 SNPs with a minor allele frequency greater than $5 \%$ and less than $10 \%$ missing data were selected and used to build a dendrogram using hierarchical clustering. From this analysis we observe four distinct groupings largely reflecting row and improvement status (Supplementary Fig. 1a). P. striiformis infects the leaves of cereals in a stepwise infection process that begins with intercellular colonization of leaves and then transitions to pustule formation ${ }^{49}$. Phenotyping was carried out using macroscopic chlorosis and infection on a nine-point scale ( 0 to $4,0.5$ increments) that correlated with the surface area exhibiting yellowing or pustule formation, respectively ${ }^{47}$. Cultivar and landrace barley accessions were highly resistant to wheat stripe rust. We observed that tworow elite barley accessions were highly resistant to Pst with only one accession exhibiting minor pustule formation. Only 14 accessions (22\%) in this group displayed a chlorotic phenotype and no leaf was observed with greater than $50 \%$ chlorosis. The observation of near complete resistance to Pst among the two-row elite accessions contrasted with an increased occurrence of susceptibility in the wild accessions. Of the 27 accessions in the wild barley group, 23 (85\%) exhibited varying degrees of chlorosis and, of these accessions, nine (33\%) allowed pustule formation. The groups representing two-row landraces and six-row barley accessions displayed varying phenotypes, containing both fully resistant and fully susceptible accessions. We extended our analysis to include two diverse panels of barley: (1) a subset of the AGOUEB panel that includes 196 domesticated, 2-row springtype elite barley cultivars from Europe ${ }^{50}$ and (2) the WBDC panel that encompasses 313 accessions of wild barley $(H$. vulgare subsp. spontaneum $)^{51}$. Inoculation of both panels with Pst isolate 08/21 found that while half of accessions in the AGEOUB panel show chlorosis $(98 / 196 ; 50 \%)$, no accession showed pustule formation (Supplementary Fig. 1b, c). In contrast, almost all accessions in the WBDC panel show chlorosis $(301 / 313$; 96\%) and approximately one third of accessions showed pustule formation (101/ 313; 32\%) (Supplementary Fig. 1d, e). From these results, we conclude that domestication has contributed to a differentiation in host status of barley to Pst isolate $08 / 21$.

Three major loci confer resistance to Pst isolate $08 / 21$ in the cultivar Golden Promise. The two-row spring barley cultivar Golden Promise was resistant to Pst, while the accession SusPtrit was fully susceptible (Supplementary Fig. 1a; Supplementary Data 1). SusPtrit was developed as a highly susceptible barley accession by selecting transgressive segregants from crosses between landraces ${ }^{52}$. The SusPtrit $\times$ Golden Promise doubledhaploid $(\mathrm{DH})$ population has been used to investigate the genetic architecture of resistance to several non-adapted Puccinia spp. ${ }^{45,53}$. To identify loci conferring resistance to Pst in the cultivar Golden Promise, we inoculated the DH population with Pst isolate $08 / 21$, phenotyped using macroscopic phenotypes and a complementary complimentary pair of microscopic phenotypic assays, pCOL and pPUST $^{47}$, and performed linkage analysis. Three significant loci on chromosomes $1 \mathrm{H}, 4 \mathrm{H}$, and $7 \mathrm{H}$ contribute to resistance (Fig. 1A; Supplementary Data 2). The chromosome $7 \mathrm{H}$ locus corresponds to the previously characterized Pst resistance locus Rps6 $6^{54,55}$, whereas the loci on chromosomes $1 \mathrm{H}$ and $4 \mathrm{H}$ are near the barley powdery mildew $(B g h)$ resistance loci $M l a(1 \mathrm{H})$ and $m l o(4 \mathrm{H})^{56,57}$. We designated the loci on chromosomes $1 \mathrm{H}$ and $4 \mathrm{H}$ as Reaction to Puccinia striiformis 7 (Rps7) and Rps8, respectively.

Collectively, these loci explain the majority of the phenotypic variation for colonization by Pst and loss of all three loci leads to infection (pustule formation) by Pst. Rps6, Rps7, and Rps8 collectively explained 62 and $67 \%$ of phenotypic variation with 
respect to chlorosis (CHL) and colonization resistance (pCOL), but only 32 and $30 \%$ of infection (INF) and pustule formation (pPUST) (Supplementary Data 2). Rps6 and Rps7 provide complete resistance, preventing fungal hyphal colonization and pustule formation (Fig. 1B). In contrast, Rps 8 in isolation permits a greater degree of colonization but prevents pustule formation (Fig. 1B). DH lines that lack all three loci display a fully susceptible interaction similar to SusPtrit, whereas strong resistance in Golden Promise is recapitulated in $\mathrm{DH}$ lines that possess all three loci. Taken together, these results demonstrate that a simple genetic architecture of three genes underlies resistance in Golden Promise: Rps6 and Rps7 confer resistance to early hyphal colonization, whereas $R p s 8$ restricts the pathogen during pustule formation.

Rps6, Rps7, and Rps8 are present in diverse barley accessions and are principal components of resistance to Pst isolate $08 / 21$. To compare these findings with the genetic architecture of resistance in other barley germplasm, we inoculated the Foster $\times$ CIho 4196 recombinant inbred line (RIL) population and Haruna Nijo $\times$ OUH602 DH population with Pst. Composite interval mapping revealed that $R p s 6, R p s 7$, and $R p s 8$ were also prominent in these two unrelated mapping populations (Supplementary Data 2). The major component of resistance in both populations was Rps7, explaining 38 and $71 \%$ of the phenotypic variation for pCOL. In line with the segregation of pustule formation in the Haruna Nijo $\times$ OUH602 DH population, Rps 8 was detected at equivalent levels to the SusPtrit $\times$ Golden Promise DH population. Rps6 was detected as a weaker QTL in the Foster $\times$ CIho 4196 population. Additional minor effect QTLs were not consistent across the different populations.

The observation of Rps6 and Rps7 in CIho 4196 and all three genes in Haruna Nijo suggested that these loci are more widely conserved in diverse barley germplasm. We assessed the frequency and prevalence of these genes by expanding our mapping efforts to a panel of accessions that encompasses the broader genetic diversity of barley, including wild barley. Using markers at Rps6, Rps7, and $R p s 8$, we assayed the presence of these loci in 31 populations from a total of 25 diverse wheat stripe rustresistant barley accessions crossed with susceptible accessions (Supplementary Data 2, 3, 4, and 5). Rps6, Rps7, and Rps8 were found to varying degrees across barley diversity (Fig. 2). Rps7 was observed in $56 \%(14 / 25)$ of the accessions analyzed. In five instances, Rps7 was detected independent of Rps6 and Rps 8 with effect sizes ranging from 10 to $95 \%$ percent variation explained (PVE) with respect to colonization resistance (Supplementary Data 2, 3, and 4). Among the wild barley accessions, WBDC172 was the only one in which Rps7 was detected, suggesting that this gene may exist at lower frequency in wild accessions. Rps6 was detected at a similar frequency, contributing to resistance in $44 \%$ $(11 / 25)$ of the accessions. When detected, Rps6 had large effect sizes in the majority of accessions (9/11). Rps 8 was detected in $60 \%(15 / 25)$ of the accessions. Rps 8 was observed in isolation from $R p s 7$ and $R p s 6$ in three accessions with effect sizes ranging from 22 to $31 \%$ PVE for colonization and 12 to $60 \%$ for pustule formation resistance. In the presence of Rps6 and/or Rps7, Rps 8 consistently had smaller effect sizes due to epistasis and is likely to be present in more populations. Three two-row cultivars, Haruna Nijo, Golden Promise, and Emir, provided evidence of all three genes functioning together in the same accession. The only accession to exhibit resistance in the absence of Rps6, Rps7, and $R p s 8$ was Duplex, indicating that additional resistance genes exists in this accession. Taken together, these results suggest that three major loci govern resistance to Pst isolate $08 / 21$ in wild, landrace, and cultivar barley accessions. The prevalence of the loci and their major contribution to resistance in all but one accession suggest that they are the principal components of resistance in barley and that reduced representation of Rps6, Rps7, and Rps8 in wild barley accessions is associated with greater susceptibility to wheat stripe rust.

Coupling of barley powdery mildew and wheat stripe rust resistance at the $\mathrm{Mla}$ locus. Considerable genetic resources have been developed to characterize the Mla locus, including several panels of near-isogenic lines (NILs) that have been created using three recurrent barley cultivars: Manchuria ${ }^{58}, \mathrm{Pallas}^{59}$, and Siri ${ }^{60}$. While the cultivars Pallas and Siri are resistant to Pst isolate 08/ 21, Manchuria is susceptible. To test for colocalization of Rps7 with diverse $M l a$ alleles, we challenged paired NILs with introgressed mildew resistance genes including six Mla alleles (Mla1, Mla6, Mla7, Mla10, Mla13, and Mla15) ${ }^{58}$. The NILs harboring Mla7 (CI 16147) and Mla15 (CI 16153) were completely resistant to Pst isolate 08/21, whereas their paired mildew susceptible partners, CI 16148 and CI 16154, respectively, were completely susceptible to Pst isolate 08/21 (Supplementary Fig. 2). Furthermore, the Mla1, Mla6, Mla10, and Mla13 haplotypes were all susceptible to Pst isolate 08/21. These paired differential NILs indicate close linkage between Mla and Rps7.

To resolve the association of barley powdery mildew and wheat stripe rust resistance at the Mla locus, we performed highresolution recombination screens using two crosses, CIho $4196 \times$ Morex and CI $16153 \times$ Manchuria using the flanking markers K_963924 and K_206D11 (Fig. 3A). In the CIho $4196 \times$ Morex recombination screen, 24 recombinants were identified from 1,136 gametes, whereas in the CI $16153 \times$ Manchuria recombination screen, 93 recombinants were identified from 2,634 gametes. $\mathrm{F}_{3}$ families derived from recombinant $\mathrm{F}_{2}$ individuals in the $\mathrm{CI}$ $16153 \times$ Manchuria population were inoculated with barley powdery mildew isolate CC148 (avirulent to Mla15) and Mla15 was confirmed to map to the Mla locus. These high-resolution recombination screens confirmed Rps7 is in coupling with Mla (Fig. 3B).

Mla is encoded by members of the RGH1 gene family, although many haplotypes are known to contain copies of two additional NLR gene families at the locus $(R G H 2 \text { and } R G H 3)^{30}$. Using a dense panel of markers, we confirmed suppressed recombination over the interval containing all three NLR encoding gene families at Mla (Fig. 3C) ${ }^{57}$. Therefore, the Mla allele is predictive of the entire haplotype as it is inherited as a single unit. To discover the Mla alleles present in our diverse barley accessions, we utilized existing de novo leaf transcriptome assemblies ${ }^{32,61}$. Accessions CIho 4196, Betzes, Golden Promise, and Haruna Nijo harbor Mla8, whereas CI 16147, CI 16153, and I5 harbor Mla7. We confirmed previous observations that Mla7 and Mla15 encode the same protein ${ }^{31}$, although we found a two amino acid differences relative to the published sequence ${ }^{62}$. A sequence similar to $R G H 3$ was found to be present using comprehensive sequence captures targeting the entire Mla locus of accessions Golden Promise and CI 16153. Evaluation of RNAseq data found that $R G H 3$ was not expressed in the accessions with available data harboring Mla7 or Mla8. RGH2 was not present in either Golden Promise or CI 16153 based on sequence capture and RNAseq. Evaluation of the Mla8 haplotype in the recently sequenced Golden Promise genome ${ }^{63}$ found that both $R G H 2$ and $R G H 3$ are absent from the region encompassing Mla8.

Copy number variation in Mla alleles. The Mla locus in the reference barley cultivar Morex contains a tandem duplication of $39.7 \mathrm{~kb}$ that contains $R G H 1, R G H 2$, and $R G H 3$ family members. To assess copy number variation of Mla7 and Mla8, digital 


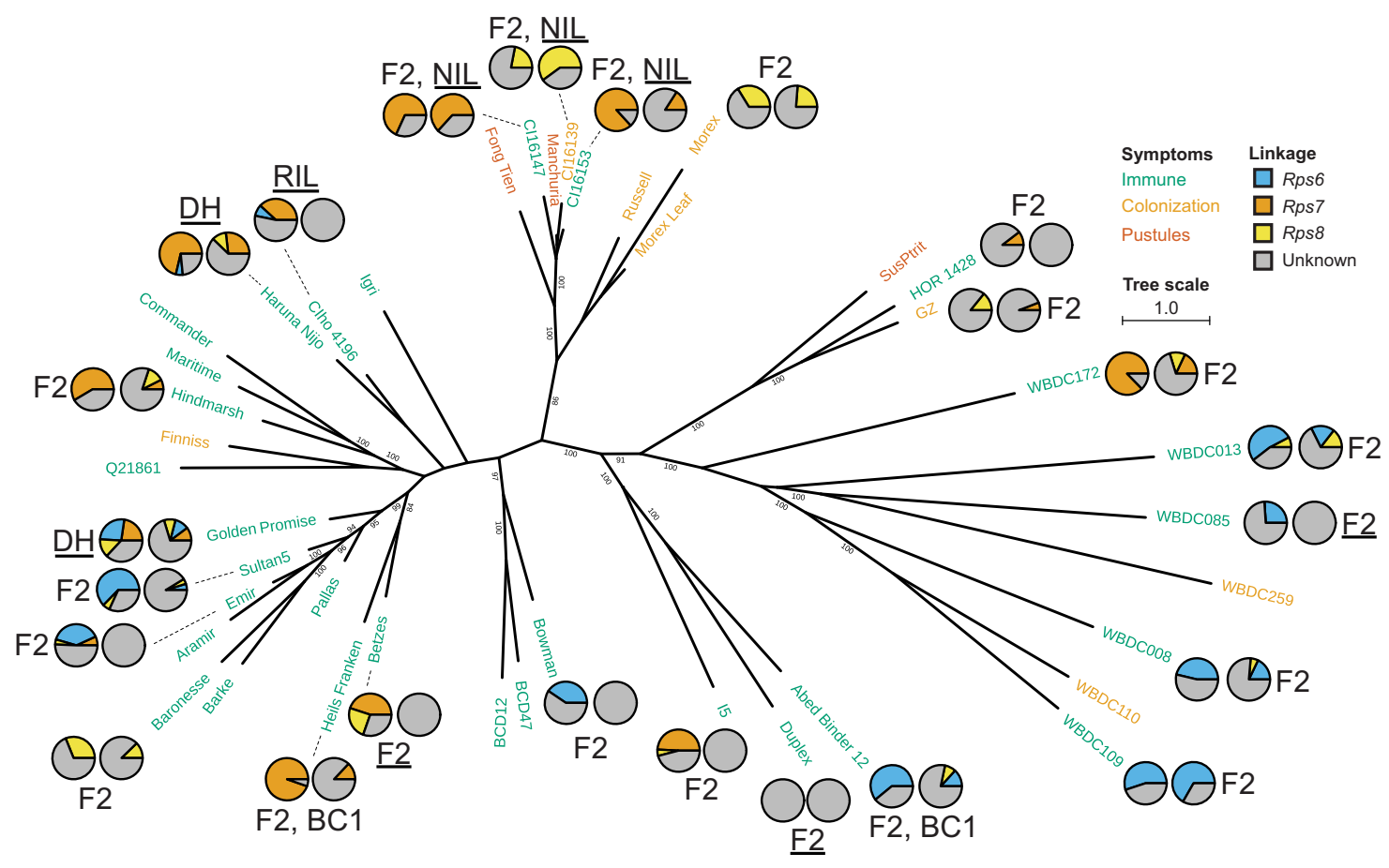

Fig. 2 Rps6, Rps7, and Rps8 are present throughout diverse barley accessions. Phylogenetic tree was generated with maximum likelihood based on SNP calling using leaf RNAseq derived from 41 genotypes. A control included RNAseq from Morex leaf. A total of 19,429 polymorphic sites were used for construction of the tree. Support over $80 \%$ is shown at branch points in the phylogeny based on 1,000 bootstraps. Scale indicates number of nucleotide substitutions. Coloring of genotypes is based on their reaction to P. striiformis f. sp. tritici isolate 08/21: immunity (green), colonization (yellow), and pustule formation (dark orange). Pie charts represent percent variation explained (PVE) for significant marker-trait associations (Supplementary Data 2, 3, 4). Two pie charts are shown for each population analyzed using two microscopic phenotypes, with the left and right chart representing percent colonization and percent pustule formation, respectively, with the exception of the Manchuria $\times$ Sultan 5 population, where macroscopic chlorosis and infection phenotypes were used. Mapping populations include $\mathrm{F}_{2}, \mathrm{BC}_{1}$, doubled-haploid, and recombinant inbred line populations. Underlined populations indicate comprehensive genetic maps were constructed, otherwise marker-trait associations were performed on markers near the Rps6, Rps7, and Rps8 loci. For accessions with multiple populations, the $F_{2}$ population was used to estimate PVE. Data not shown for HOR 2926 due to lack of RNAseq data. GZ $=$ Grannenlose Zweizeilige. Source data are provided as a Source Data file.

droplet PCR was performed on a range of barley accessions containing Mla8, two independent sources of Mla7 (accessions Multan and Long Glumes), their corresponding Manchuria nearisogenic lines (CI 16147 and CI 16153), and CI 16155 (Manchuria NIL Mla13). Mla8 was present in a single copy across all accessions tested that harbor Mla8 (Supplementary Fig. 3a). The coding sequence of Mla13 shares $97.8 \%$ sequence identity with Mla7 and has only two nucleotide differences with the RGH1 allele in SxGP DH-47 (RGH1.SusPtrit). Using two independent primer pairs that amplify Mla7, Mla13, and RGH1.SusPtrit, we found that Mla13 and RGH1.SusPtrit exist as single copies in CI 16155 and SxGP DH-47, respectively. In contrast, higher order copy number variation was observed in lines expressing Mla7, with an estimate of at least three copies (Supplementary Fig. 3b). We conclude that Mla8 exists as a single-copy gene, whereas the Mla7 and Mla15 haplotypes expressing Mla7 have multiple, identical copies.

Mla8 confers resistance to barley powdery mildew and wheat stripe rust in barley. We hypothesized that Mla has dual functionality for resistance to barley powdery mildew and wheat stripe rust. To test this hypothesis, we integrated the open reading frames of Mla1, Mla6, and Mla8 into the native Mla6 genomic segment containing promoter, UTR, and terminator sequence (p6:Mla:t6) and transformed the barley powdery mildew and wheat stripe rust susceptible, transformable line SxGP DH- $47^{53}$ (Supplementary Fig. 4). For Mla8 transgenic families, advanced progeny in two independent families were identified that were homozygous for the T-DNA insert or null. To determine whether transgenic lines carrying these Mla alleles maintain resistance and race-specificity to barley powdery mildew, we inoculated transgenic lines carrying Mla1, Mla6, and Mla 8 with 13 diverse Bgh isolates that vary for their corresponding avirulence genes $A V R_{a 1}$, $A V R_{a 6}$, and $A V R_{a 8}$. All transgenic lines harboring single copies of Mla1, Mla6, and Mla8 transgenes retained their specificity to recognize barley powdery mildew with corresponding $A V R_{a}$ genes based on a collection of 13 diverse isolates (Fig. 4; Supplementary Data 6). This work shows that the Mla6 promoter is sufficient for expression of Mla1, Mla6, and Mla8.

To test whether transgenic barley expressing Mla8 confer resistance to wheat stripe rust, we challenged progeny from primary transgenic lines of Mla1, Mla6, and homozygous Mla8 transgenic lines with wheat stripe rust isolate 16/035. Resistance to wheat stripe rust was only observed in transgenic lines carrying Mla8, whereas Mla1 and Mla6 did not confer resistance (Fig. 5A, B). Advanced transgenic families carrying single-copy inserts of Mla 8 were challenged with wheat stripe rust isolates $08 / 21$ and $15 /$ 151 (Fig. 6A-C,E), and in both instances, conferred resistance. When challenged with barley stripe rust isolate B01/2 the transgenic lines carrying Mla8 exhibited similar levels of susceptibility as controls (Fig. 6D, F). Mla1 and Mla8 are very similar (97.4\%), with sequence variation only present in the LRR-encoding region. This indicates that the allelic specificity to barley powdery mildew and wheat stripe rust is determined by this $522 \mathrm{bp}$ region. Therefore, we conclude that Mla8 has dual specificity in recognition of barley powdery mildew and wheat stripe rust. 


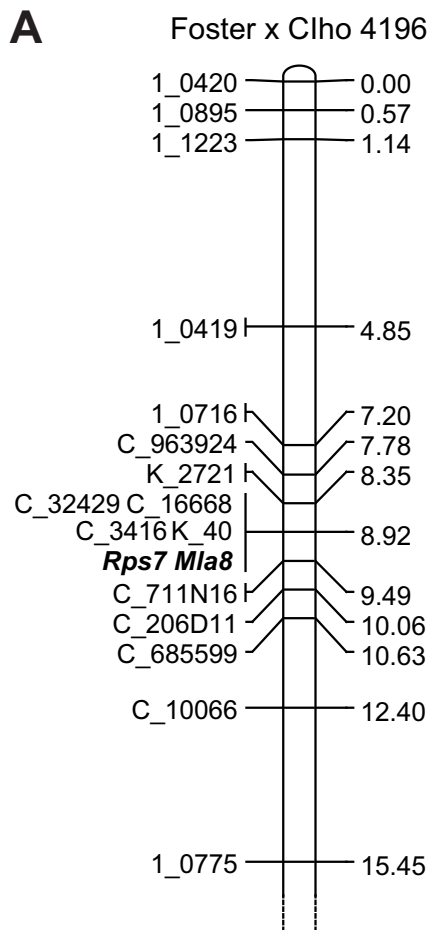

B Clho $4196 \times$ Morex Cl $16153 \times$ Manchuria

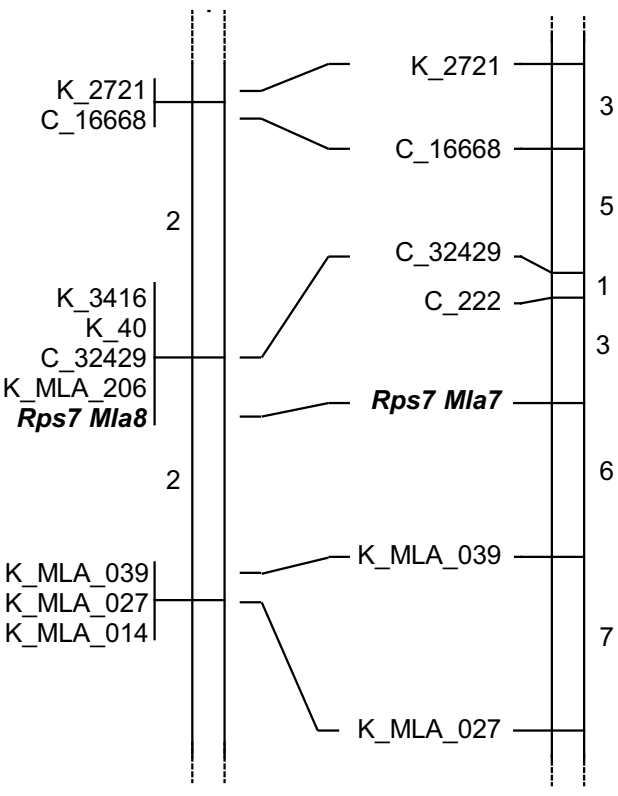

\section{Morex (RGH1bcd)}

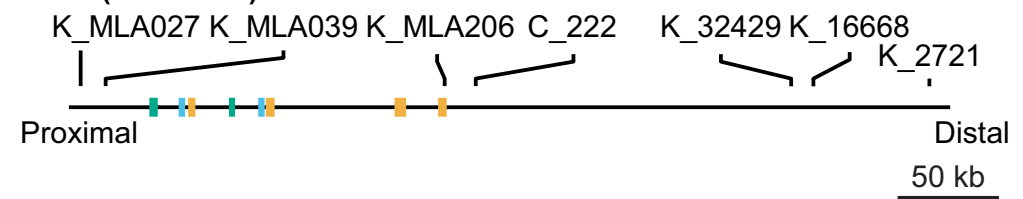

Golden Promise (Mla8)

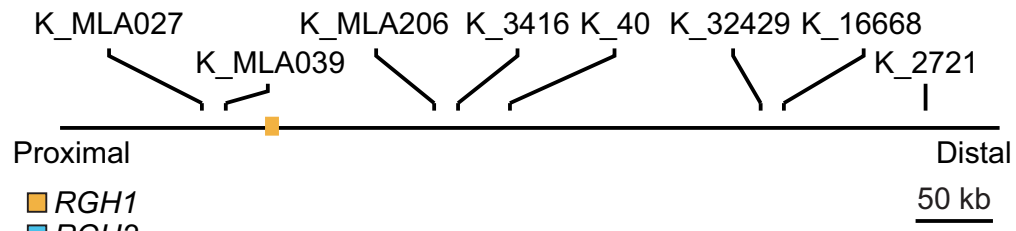

$\square R G H 2$

$\square R G H 3$

Fig. 3 Rps7 is in complete coupling with Mla. A Genetic map of the Foster $\times$ Clho 4196 recombinant inbred line population encompassing the Mla8/Rps 7 locus. Markers K_963924/C_963924 and K_206D11/C_206D11 were used for recombination screens. Genetic distances are in cM. Prefixes designate marker type: C: Cleaved Amplified Polymorphic Sequences (CAPS) and K: Kompetitive allele-specific PCR (KASP). B High-resolution recombination screens were performed to resolve the relationship of Mla and Rps7. Recombination screens CI $16153 \times$ Manchuria and Clho $4196 \times$ Morex included 1,136 and 2,634 gametes, respectively. Rps7 was resolved to an interval defined by K_MLA_039 and C_16668 in the Clho $4196 \times$ Morex population and K_MLA_039 and C_222 in the Cl $16153 \times$ Manchuria population. Values between markers indicate the total number of recombinants identified. C Physical interval of Mla locus from the reference barley cultivar Morex that contains four RGH1 genes (RGH1a, RGH1bcd, RGH1e, RGH1f) and Golden Promise that contains one RGH1 gene (Mla8). In Morex, the markers K_MLA_039 and K_16668 define a physical interval of 360 kb that includes all three NLR gene families at the Mla locus (RGH1 (orange), RGH2 (blue), and RGH3 (green)). In Golden Promise, the markers K_MLA_039 and K_16668 span a physical interval of $358 \mathrm{~kb}$ that includes only a single copy of $R G H 1$ (Mla8).

\section{Discussion}

We discovered that two distinct haplotypes of Mla have coupled resistance to the adapted pathogen barley powdery mildew (Bgh; ascomycete) and non-adapted pathogen wheat stripe rust (Pst; basidiomycete). The majority of Mla haplotypes did not recognize Pst, suggesting that recognition resembles a similar haplotype specificity as observed for Bgh. Previous work demonstrated that an Mla ortholog in Triticum monococcum confers resistance to wheat powdery mildew (B. graminis f. sp. tritici) in transient assays $^{36}$, whereas Mla orthologs in Aegilops tauschii (Sr33) and rye $(S r 50)$ confer resistance to wheat stem rust ( $P$. graminis $\mathrm{f} . \mathrm{sp}$. tritici) ${ }^{35,37}$. Interaction studies have shown direct interaction between MLA/AVR effectors in barley powdery mildew $^{40,64}$ and Sr50/AvrSr50 $0^{39}$. Taken together, the Mla gene family has the broad capacity to recognize effectors from a diversity of ascomycete and basidiomycete pathogens. Based on linkage with resistance to rice blast ${ }^{65}$ and susceptibility to spot blotch ${ }^{66}$, this recognition spectrum of the barley Mla locus may be even greater.

The genetic coupling of resistance to different pathogen species at NLR loci has been observed in only a few systems ${ }^{67}$. Mi from tomato confers resistance to root knot nematode (Meloidogyne spp. ${ }^{68}$, potato aphid (Macrosiphum euphorbiae), and whitefly 
A
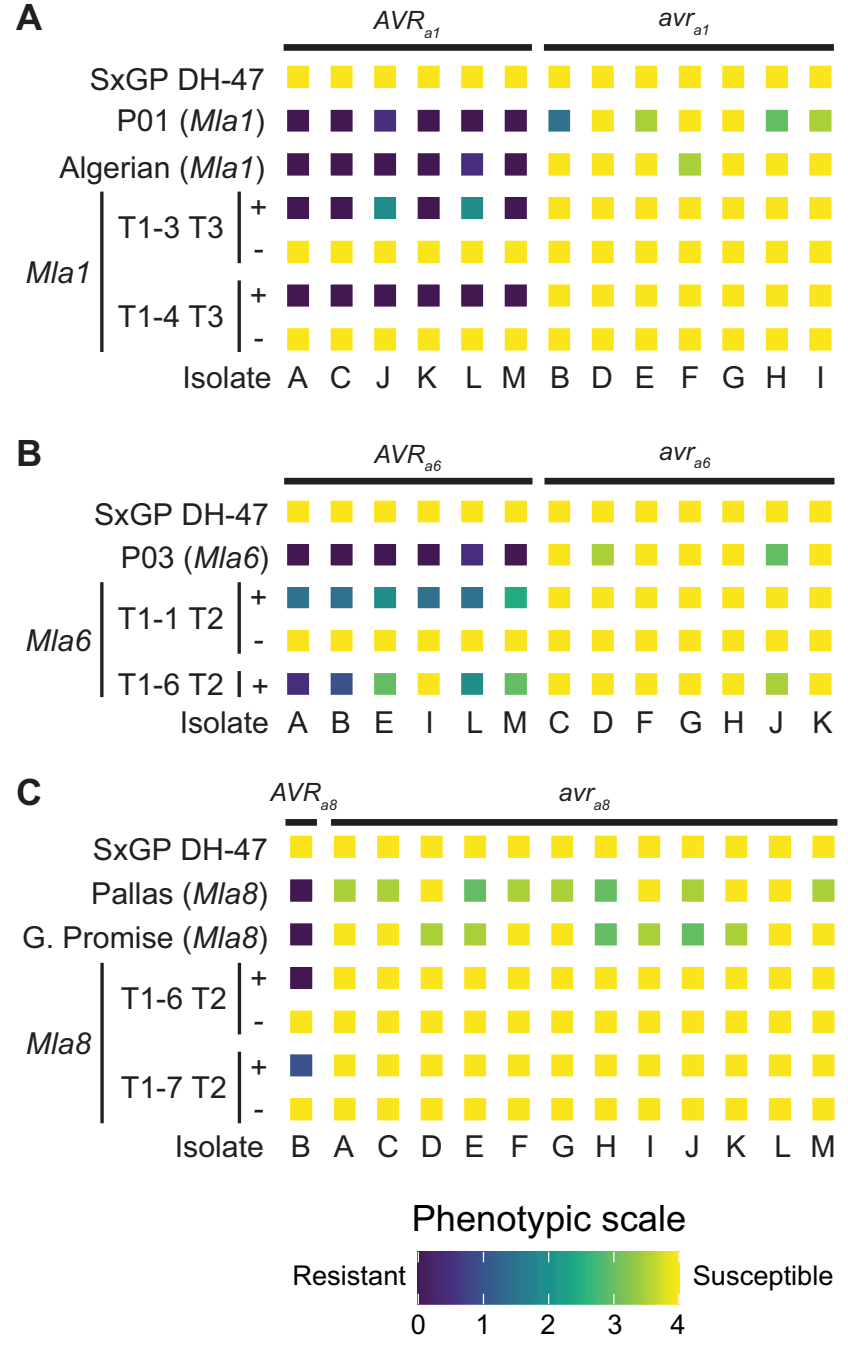

Fig. 4 Mla transgenes maintain race-specific resistance to barley powdery mildew (Blumeria graminis f. sp. hordei). Independent transformants of barley cv. SxGP DH-47 with (A) Mla1, (B) Mla6, and (C) Mla8 driven by the Mla6 promoter and Mla6 terminator were inoculated with 13 diverse barley powdery mildew isolates. SxGP DH-47 was susceptible to all isolates. Single T-DNA insertions were sufficient to confer race-specific resistance to barley powdery mildew for Mla1, Mla6, and Mla8. Controls include Pallas (Mla8), near-isogenic lines in the Pallas genetic background: P01 (Mla1), P03 (Mla6), Algerian (Mla1), and Golden Promise (Mla8). For individual Mla alleles, barley powdery mildew isolates are ordered based on the presence (AVR) or absence (avr) of an avirulence gene. Isolates include 3-33 (A), Race I (B), X-4 (C), I-167 (D), K-200 (E), M-236 (F), Z-6 (G), C-132 (H), $120(\mathbf{I}), \mathrm{R} 86 / 1(\mathbf{J}), \mathrm{K}-3(\mathbf{K}), \mathrm{KM} 18(\mathbf{L})$, and $\mathrm{MN}-\mathrm{B}(\mathbf{M})^{86}$. All experiments were performed twice with similar results and data shown is the average of these experiments. Original data is provided as Supplementary Data 6.

Bemisia argentifolii ${ }^{26}$. In Arabidopsis thaliana, multiple pathogen recognition at the RPS4/RRS1 locus confers resistance to the bacterial pathogens Pseudomonas syringae, Ralstonia solanacearum, Xanthomonas campestris, and the fungal pathogen Colletotrichum higginsianum ${ }^{24,69}$. NLR recognition of taxonomically diverse pathogens that do not share a common effector repertoire suggests that either (1) effectors from these pathogens contain a conserved structure that directly interacts with the NLR, (2) the NLR has the capacity to recognize different effectors through different binding sites, or (3) the NLR guards a host protein that is a shared effector target by multiple pathogens. In the latter model of recognition, these effectors may or may not be structurally related. In A. thaliana, recognition of $P$. syringae and $R$. solanacearum by the NLR pair RPS4 and RRS1 requires the WRKY domain of RRS1, and requires the effectors AvrRps4 and PopP2, respectively ${ }^{70,71}$. While the corresponding effector from C. higginsianum is not known, AvrRps4 and PopP2 are sequence unrelated, suggesting that the WRKY domain is a conserved target by multiple pathogens. An initial analysis of the Pst genome $^{31}$ did not identify a homolog of cloned $\mathrm{AVR}_{\mathrm{a}}$ proteins ${ }^{38,40,64}$ of barley powdery mildew. In the present study, we favor the first and second models of recognition, based on previous work that has found that the majority of MLA proteins likely bind their corresponding $\mathrm{AVR}_{\mathrm{a}}$ directly ${ }^{40,64}$. Mla1 is functional against barley powdery mildew when transferred to Arabidopsis thaliana, which further supports a model of direct interaction with an effector ${ }^{72}$. Lastly, it is possible that different alleles of MLA may have differing modes of recognition, as MLA9 unlike other tested MLA proteins, was found to not elicit an HR when heterologously expressed with its corresponding effector in Nicotiana benthamiana ${ }^{40}$. Identification of the recognized effector in wheat stripe rust will be essential to establish the mode of recognition.

Genetic coupling at Mla demonstrates that selection for resistance to one pathogen can directly influence resistance to other pathogens, including non-adapted pathogens. The implications of multiple pathogen recognition suggest that selection for one pathogen could lead to greater resistance (mutualistic) or susceptibility (antagonistic) to another pathogen. Mla is a target of breeding, often through the introduction of exotic alleles from wild barley 33,73 . As we observed considerable susceptibility in wild barley, it suggests that the majority of Mla alleles present in these accessions do not confer resistance to wheat stripe rust (Supplementary Data 7). More broadly, marker-assisted selection and the fixation of resistance genes in plant breeding programs are routine ${ }^{74}$ and there is a risk associated with not understanding the broader capacity of resistance genes in maintaining a barrier to host range dynamics. As plant breeders seek to incorporate novel sources of resistance from primary, secondary, and tertiary gene pools of crop species, they also expose agricultural systems to the introduction of susceptibility genes or the removal of genes that maintain barriers to non-adapted pathogens. As marker-assisted selection is often used for the incorporation of exotic alleles, a novel form of susceptibility may not be detected until after the release of a cultivar, as was observed for the host jump of Victoria blight (Bipolaris victoriae) onto oats containing the oat crown rust resistance gene $P c 2^{75}$ and the host range expansion of blast (Pyricularia oryzae) through the wheat cultivar Anahuac, which lacked a crucial resistance gene ${ }^{76}$. The implication of multiple pathogen recognition in host species specificity highlights the potential impact of current plant breeding practices to host range expansions.

Barley is grown in temperate regions of the world and occupies an agricultural niche similar to wheat ${ }^{77}$. Thus, barley, inevitably, is exposed to great inoculation potential of wheat-adapted pathogens. Despite this, barley remains highly resistant to nonadapted $P s t$ yet is readily infected by the adapted form, $P s h^{78,79}$. A critical example of the durability of resistance is found in Australia, where neither wheat stripe rust nor barley stripe rust were present until 1979 when $P s t$ was introduced ${ }^{78}$. Despite high pathogen pressure, Pst has not made a host jump onto barley. The introduced Pst in Australia is genetically similar to Pst isolate 08/ $21^{80,81}$. Several barley accessions used in this work, including Commander, Maritime, Hindmarsh, and Finniss are Australian cultivars, and Hindmarsh was found to carry Rps7 (Mla8) and Rps8. This raises the question, how has barley maintained resistance to Pst in Australia despite significant infection pressure in 
A

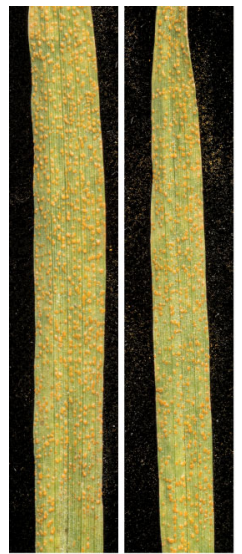

$+$

T1-3

Mla1

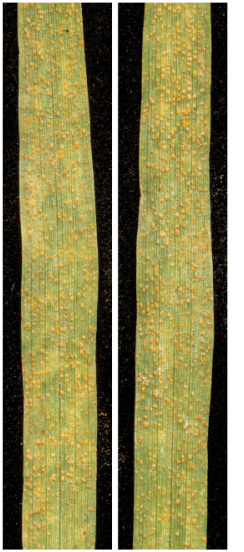

$+$

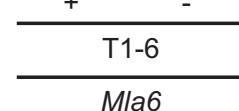

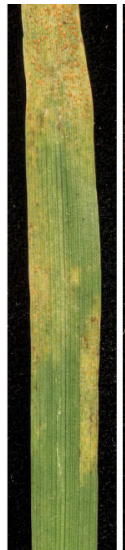

$+$

$+$

T1-6 T3
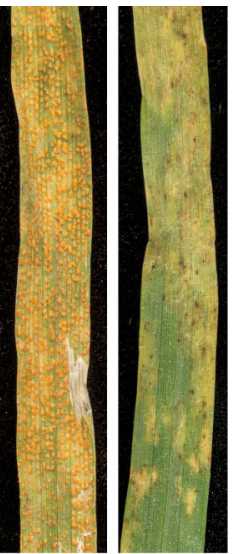

$+$

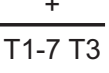

B
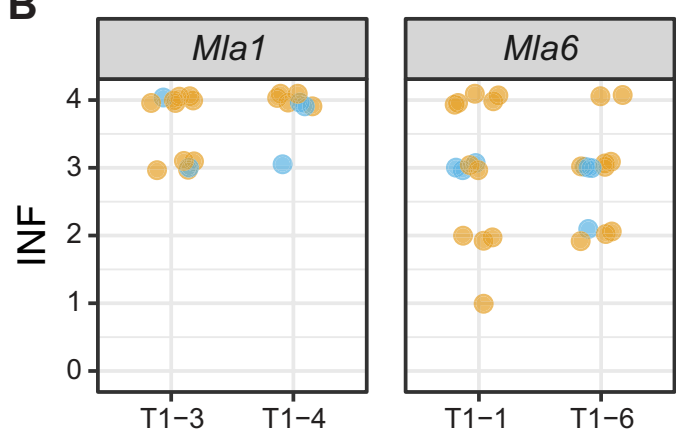

T1-1 T1-6

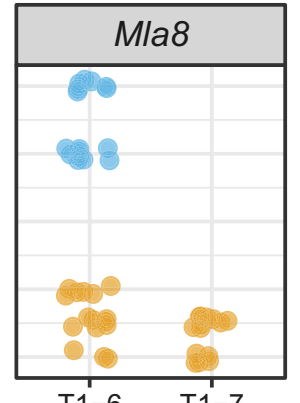

T1-6 T1-7

T3 T3
T-DNA

- Absent

- Present

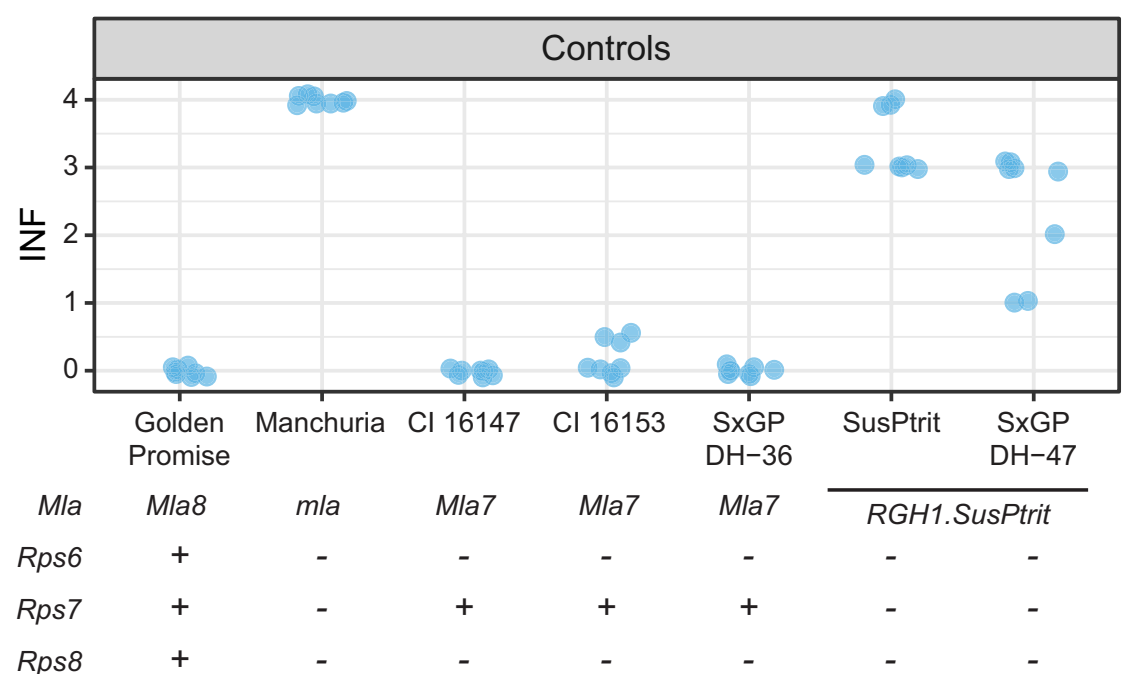

Fig. 5 Allele-specific resistance of $\mathbf{M l a}$ to wheat stripe rust (P. striiformis f. sp. tritici) isolate 16/035. Wheat stripe rust susceptible barley cv. SxGP DH47 was transformed with Mla1, Mla6, and Mla8 driven by the Mla6 promoter and Mla6 terminator. Two single-copy insert lines were identified for Mla1 (T13 and T1-4) and Mla6 (T1-1 and T1-6). For Mla8, $\mathrm{T}_{3}$ homozygous progeny present (T1-6 and T1-7) and absent (T1-6) for the transgene were used. Resistance to wheat stripe rust isolate 16/035 was observed in transgenic barley lines with single copy of Mla8 and in the controls Golden Promise (Rps6; Mla8/Rps7; Rps8), Cl 16147 (Mla7/Rps7), Cl 16153 (Mla7/Rps7), and SxGP DH-36 (Mla8/Rps7). Susceptibility to P. striiformis f. sp. tritici isolate 16/035 was observed in transgenic barley lines with T-DNA containing Mla1 and Mla6. A Representative leaf phenotypes in the presence $(+)$ or absence $(-)$ of T-DNA for individual Mla alleles. B Infection phenotypes for individual leaves in $T_{1}$ families and controls. Presence or absence of T-DNA is shown in orange and blue, respectively. All phenotypes are on a scale from 0.0 to 4.0 in 0.5 increments represent the degree of leaf area covered with pustules. Transparency and jittering were used to visualize multiple overlapping data points. An extended set of controls for $P$. striiformis f. sp. tritici isolate $16 / 035$ can be found in Supplementary Fig. 5 and 6. Source data are provided as a Source Data file. 
A Puccinia striiformis f. sp. tritici isolate 08/21 experiment 1

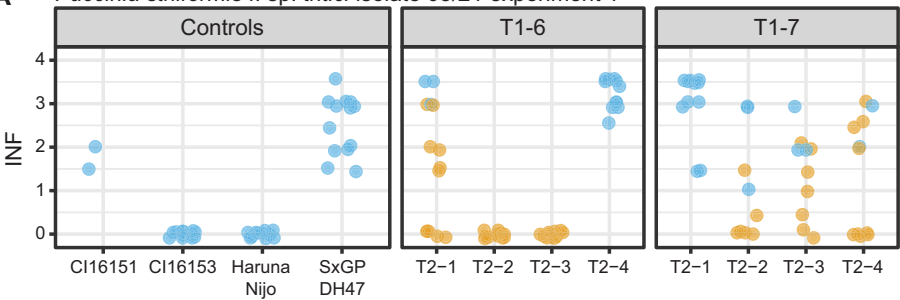

B Puccinia striiformis f. sp. tritici isolate 08/21 experiment 2
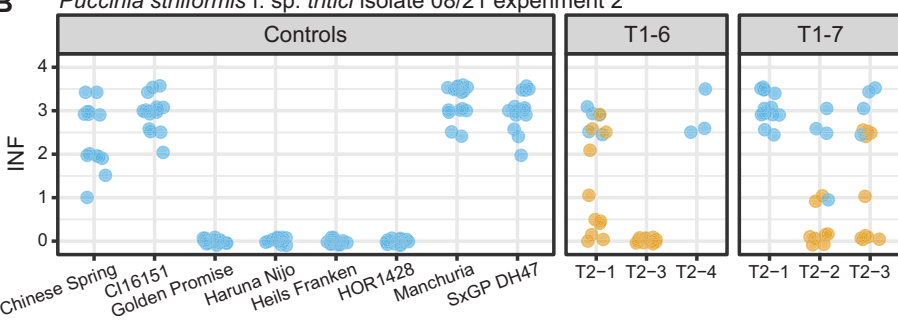

C Puccinia striiformis f. sp. tritici isolate $15 / 151$
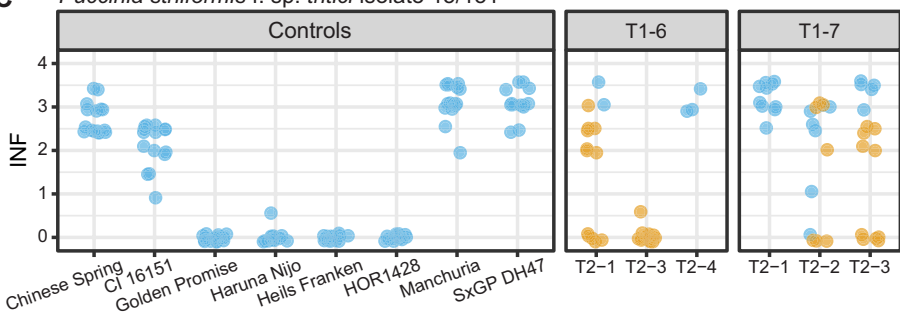

D Puccinia striiformis f. sp. hordei isolate B01/2

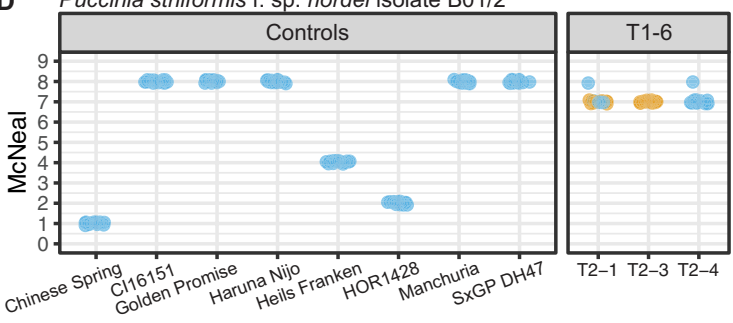

E

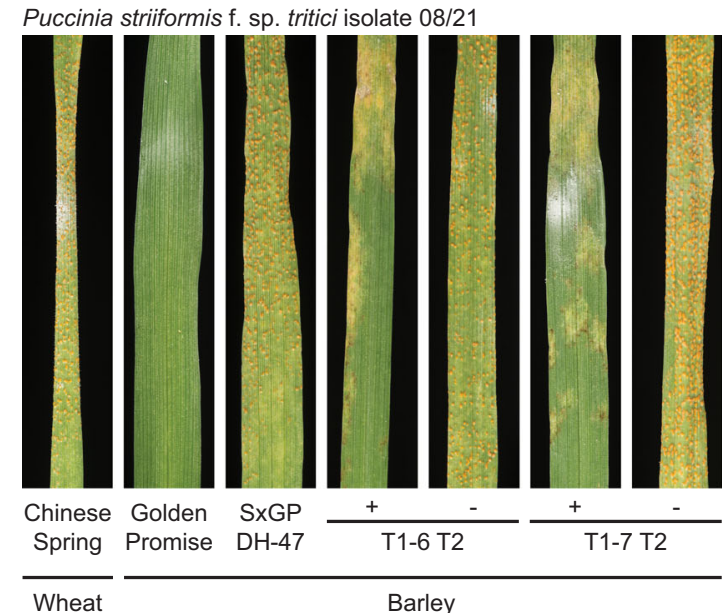

F Puccinia striiformis f. sp. hordei isolate B01/2

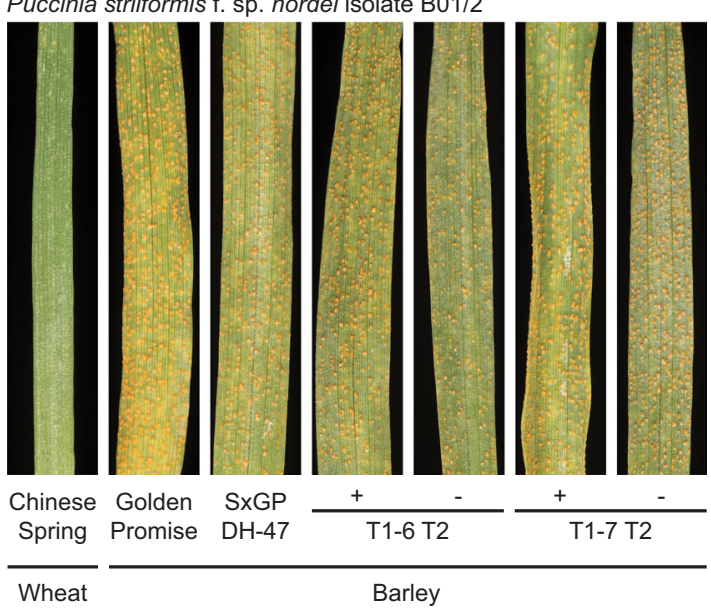

Fig. 6 Mla8 confers resistance to $P$. striiformis $\mathbf{f}$. sp. tritici isolates $\mathbf{0 8 / 2 1}$ and 15/151, but not $\boldsymbol{P}$. striiformis f. sp. hordei isolate B01/2. Advanced $T_{2}$ progeny from two independent single insert $p 6:$ Mla8:t6 transgenic families in the SxGP DH-47 genetic background were inoculated with $P$. striiformis $f$. sp. tritici isolates (A, B) 08/21 and (C) 15/151, and (D) P. striiformis f. sp. hordei isolate B01/2. Representative photos are shown for (E) P. striiformis f. sp. tritici isolate 08/21 and (F) P. striiformis f. sp. hordei isolate B01/2. Phenotypic scales used include infection (INF) for wheat stripe rust ${ }^{47}$ (0.0 to 4.0 in 0.5 increments represent the degree of leaf area covered with pustules) and the McNeal scale for barley stripe rust 90 . Presence or absence of the p6:Mla8:t6 transgene is color coded orange or blue, respectively. Transparency and jittering were used to visualize multiple overlapping data points. Progeny from transgenic family T1-6 were selfed, generating hemizygous T-DNA families (T1-6 T2-2 and T1-6 T2-3), homozygous null (T1-6 T2-1). Progeny from transgenic family T1-7 were selfed, generating homozygous T-DNA (T1-7 T2-2), hemizygous T-DNA (T1-7 T2-1), homozygous null (T1-7 T2-3). Controls include the wheat accession Chinese Spring, and barley accessions Cl16151 (rps6 rps7(=Mla6) rps8), Golden Promise (Rps6 Rps7(=Mla8) Rps8), Haruna Nijo (Rps6 Rps7(=Mla8) Rps8), Heils Franken (rps6 Rps7(=Mla37) rps8), and HOR1428 (rps6 Rps7 rps8), Manchuria (rps6 rps7 rps8) and SxGP DH-47 (rps6 rps7 rps8). Heils Franken and HOR 1428 are resistant controls to $P$. striiformis f. sp. hordei isolate B01/2. Source data are provided as a Source Data file.

the field? We hypothesize that three factors contribute to maintaining resistance. First, the majority of accessions carry multiple resistance genes against Pst. The presence of multiple genes likely contributes to their durability. Second, while Rps6, Rps7, and Rps8 were identified across both domesticated and wild barley, we also identified several minor effect QTL that varied between accessions. These loci represent a broad complex of major and minor effect resistance genes that contribute to the non-adapted status of barley. Lastly, the underlying genetic architecture that contributes to maintaining host species specificity to $P$. striiformis may change based on the developmental stage of the plant. Niks and colleagues (2013) demonstrated that barley accessions susceptible to two non-adapted $P$. striiformis at the seedling stage had variable response at the adult stage ${ }^{82}$. As only four accessions were tested with $P$. striiformis f. sp. bromi and one accession with $P s t$, additional studies are required to assess the contribution of developmentally regulated resistance in maintaining resistance to non-adapted $P$. striiformis. Further work will be required to establish the broader role of Rps6, Rps7, and Rps8 in the context of natural variation of barley and stripe rust and how the developmental stage may influence the underlying genetic architecture of immunity in barley to non-adapted stripe rust.

The coupling of resistance directly addresses a long-standing question in nonhost resistance: How can selection act on a phenotype that does not have a direct fitness benefit? If the plant immune system has the broader capacity to recognize diverse pathogen species, then selection against adapted pathogens may maintain resistance to non-adapted pathogens. Two alternative 
non-exclusive models may explain this phenomenon. First, pathogens may be able to exploit only a limited number of host targets for suppressing immunity, many of which are guarded by NLRs. Alternatively, the basis of effector function may require the adoption of a conserved structure, which is directly recognized by NLRs. With respect to the evolution of immunity, population genetic models previously focused on selection acting on single dominant $R$ genes in host systems, which lead to either recurrent purifying selection or balancing selection ${ }^{83}$. The coupling of resistance to multiple pathogens indicates that more complex models will be required to describe the selective forces driving the evolution of immunity in plants.

\section{Methods}

Plant and fungal materials. Barley accessions were obtained from diverse sources that are referenced in Supplementary Data 1. The Foster $\times$ CIho 4196 recombinant inbred line population $(N=89)$ was provided by A. Kleinhofs (Washington State University, WA, USA) ${ }^{84}$. The Haruna Nijo $\times$ OUH602 doubled-haploid population $(N=94)$ was provided by Kaz Sato (Okayama University, Okayama, Japan) ${ }^{85}$. The SusPtrit $\times$ Golden Promise doubled-haploid population was provided by Rients Niks (Wageningen University, Netherlands) ${ }^{53}$. All plants were subjected to single seed descent. Pst isolates 08/21, 15/151, and 16/035 were collected in 2008, 2015, and 2016, respectively, in the United Kingdom and maintained at the National Institute of Agricultural Botany (NIAB). Psh isolate B01/2 was collected in 2001 in the United Kingdom and maintained at NIAB. Pst and Psh isolates were increased on susceptible wheat and barley cultivars, respectively, collected, and stored at $6^{\circ} \mathrm{C}$. B. graminis f. sp. hordei isolate CC148 was collected in the United Kingdom and propagated on barley cv. Manchuria (CI 2330). A subset of 13 isolates of B. graminis f. sp. hordei was selected from a gene bank of the pathogen containing 59 reference isolates collected in 12 countries in all nonpolar continents over a period of 66 years (1953-2019) and kept at the Agricultural Research Institute Kroměříz Ltd. Virulence patterns to 35 standard barley genotypes are shown in Dreiseitl $(2019)^{86}$. Before inoculation all isolates were checked for their purity and their correct virulence phenotypes were verified on standard barley lines ${ }^{59}$. The isolates were multiplied on leaf segments of a susceptible cultivar Bowman.

Genomic DNA isolation. Genomic DNA from all populations was extracted from leaf tissue following a 96-well PCR-grade genomic DNA isolation procedure for cereal leaf tissue modified from Stewart and $\mathrm{Via}^{87}$. Second leaves were placed into a 96-well plate (Abgene, \#AB-0661) prefilled with three 5/32" stainless steel balls (OPM Diagnostics, \#SP-2150). Plates were sealed with a permeable membrane (Excel Scientific, \#B-100) and placed into a lyophyllizer (Thermo Scientific, PowerDry LL3000) for $48 \mathrm{~h}$. After removal, plates were sealed with silicon capmats and placed in a TissueLyser I bead mill (Qiagen) for $1 \mathrm{~min}$ at $1500 \mathrm{rpm}$, then reversing plate orientation and repeating the grind. Plates were spun for $2 \mathrm{~min}$ at $2500 \times g$ to remove residual powder from capmats. A CTAB extraction buffer was prepared as follows for a single plate: $0.35 \mathrm{~g}$ of CTAB, $25.5 \mathrm{~mL}$ of $\mathrm{ddH}_{2} 0,3.5 \mathrm{~mL}$ of $1.0 \mathrm{M}$ Tris at $\mathrm{pH} 8.0,4.9 \mathrm{~mL}$ of $5.0 \mathrm{M} \mathrm{NaCl}, 700 \mu \mathrm{L}$ of $0.5 \mathrm{M}$ EDTA at $\mathrm{pH} 8.0$, and $350 \mathrm{uL}$ of $14 \mathrm{M}$ 2-Mercaptoethanol. All ingredients were added in the described order, with BME added prior to genomic DNA extraction. Next, $300 \mu \mathrm{L}$ of CTAB extraction buffer was applied to each well. Plates were loaded into custom made wooden clamps and mixed several times. The entire assembly was incubated for $45 \mathrm{~min}$ at $65^{\circ} \mathrm{C}$, during which the assembly was mixed by inversion every $15 \mathrm{~min}$. Plates were spun for $1 \mathrm{~min}$ at $2500 \times \mathrm{g}, 100 \mu \mathrm{L}$ of $5.0 \mathrm{M}$ KOAc was added to each well, resealed and mixed by inversion, and placed into an ice bath for $20 \mathrm{~min}$. Plates were again spun for $1 \mathrm{~min}$ at $2500 \times \mathrm{g}$, and $150 \mu \mathrm{L}$ of chloroform:isoamyl alchohol $(\mathrm{v} / \mathrm{v}, 24: 1)$ was added to each well, resealed, placed in clamps, and mixed by inversion for $5 \mathrm{~min}$. Plates were then spun for $10 \mathrm{~min}$ at $2500 \times \mathrm{g}$ at room temperature. Approximately $200 \mu \mathrm{L}$ of the upper aqueous layer was applied to $120 \mu \mathrm{L}$ of isopropanol, resealed, inverted 20 times, and then spun for $15 \mathrm{~min}$ at 2,500 $\times \mathrm{g}$. After centrifugation, the supernatant was decanted and the plate was blotted dry. The pellet was resuspended in $200 \mu \mathrm{L}$ TE with $0.2 \mathrm{mg} / \mathrm{mL}$ of RNAse (Roche), inverted several times, and incubated for $10 \mathrm{~min}$ at $65^{\circ} \mathrm{C}$. After spinning the plate, $300 \mu \mathrm{L}$ of 7:1 isopropanol:4.4 $\mathrm{M} \mathrm{NH}_{4} \mathrm{Ac}$ was added, the plate inverted several times, and then spun for $10 \mathrm{~min}$ at $2500 \times \mathrm{g}$. After centrifugation, the supernatant was decanted and the plate was blotted dry. Pellets were rinsed with $250 \mu \mathrm{L}$ of $70 \%$ ethanol, spun for $3 \mathrm{~min}$ at $2500 \times \mathrm{g}$, decanted and blotted dry, then placed in a $65^{\circ} \mathrm{C}$ oven for $10 \mathrm{~min}$ to remove residual ethanol. The genomic DNA pellet was resuspended in $100 \mu \mathrm{L}$ of PCR-grade TE.

Pathogen assays. Pathogen assays with $P$. striiformis were performed using a suspension of urediniospores talcum powder, at a weighted ratio of spores:talcum powder of 1:16, and applied to leaves using compressed on a spinning table. Immediately after inoculation, plants were sealed in a high-density polyethylene bag and stored at $8{ }^{\circ} \mathrm{C}$ for $48 \mathrm{~h}$. The sealed environment was used to ensure high humidity. Plants were grown in the same controlled environment room before and after inoculation with the following conditions: $16 \mathrm{~h}$ light $/ 8 \mathrm{~h}$ dark), with day temperature of $18^{\circ} \mathrm{C}$ and night temperature of $11^{\circ} \mathrm{C}$. Lighting was supplied by halogen light bulbs. Experimental design for mapping population involved four groups of eight seeds planted in different equidistant quadrants in a $1 \mathrm{~L}$ pots using a peat-based compost. Seedlings were were macroscopically phenotyped 14 days post-inoculation and the first leaf sampled for microscopic phenotyping.

Pathogen assays using the diverse collection of $B g h$ isolates, inoculation and evaluation was previously described ${ }^{88}$. Briefly, seeds of transgenic families were planted in gardening peat substrate in an $80 \mathrm{~mm}$ diameter pot $(80 \mathrm{~mm}$ diameter) and grown in a mildew-proof greenhouse under natural daylight. After 14 days, $15 \mathrm{~mm}$ leaf segments were taken from the center of fully expanded first leaves (second leaf just emerging). For each transgenic family and controls, three segments were arrayed along with four segments of the susceptible cultivar Bowman oriented diagonally. Leaves were placed with adaxial surfaces facing up in a $150 \mathrm{~mm}$ Petri dish on water agar $(0.8 \%)$ containing benzimidazole $(40 \mathrm{mg} / \mathrm{L})$, a leaf senescence inhibitor. Inoculation was performed by placing leaf segments at the bottom of a cylindrical metal settling tower $(150 \mathrm{~mm}$ diameter, $415 \mathrm{~mm}$ height). Conidiaspores from fully developed pathogen colonies grown on cultivar Bowman were harvested by manual shaking onto a square piece $(40 \times 40 \mathrm{~mm})$ of black paper to visually estimate the amount of inoculum. A blowpipe was formed by rolling the paper, and blown through a side hole of $13 \mathrm{~mm}$ diameter in the upper part of the settling tower over the Petri dish at a concentration of approximately 8 conidia $/ \mathrm{mm}^{2}$. Dishes with inoculated leaf segments were placed in a controlled environment room with $20 \pm 2{ }^{\circ} \mathrm{C}$ under artificial light (cool-white fluorescent lamps providing $12 \mathrm{~h}$ light at $30 \pm 5 \mu \mathrm{mol} \mathrm{m}^{-2} \mathrm{~s}^{-1}$ ). Infection responses (IR; virulent/avirulent) were scored at seven days after inoculation on the central part of leaf segments on a scale $0-4$, where 0 is equivalent to no visible mycelium or sporulation, and 4 represents strong mycelial growth and sporulation ${ }^{89}$. Scoring was repeated one day later, and significant differences were rescored. A total of two replications were performed for all lines. A set of 13 reaction types provide an infection response array (IRA) for each line and hypothetical resistance gene specificity in tested lines were postulated by comparing their IRAs with known IRAs of barley genotypes possessing known resistance genes.

Macroscopic phenotyping. For Pst, macroscopic symptoms were evaluated on the first leaf of all seedlings at 14 days post-inoculation based on chlorosis and infection (presence of fungal pustules), both scored on a scale of 0 to 4 , with increments of 0.5 . In both cases, the phenotypic scale reflects the surface area expressing the phenotype. A score of 0 was symptomatic of no expression of the phenotype, i.e. no chlorosis or no pustules, and a score of 4 was indicated full expression (i.e. $100 \%$ of the surface area). For Pst, macroscopic symptoms were evaluated on the first leaf of all seedlings at 14 days post-inoculation using the $\mathrm{McNeal}$ scale ${ }^{90}$. For B. graminis f. sp. hordei, macroscopic symptoms were evaluated on the first leaf of all seedlings at 7 days post-inoculation based on the surface area of leaf covered by colonies, scored on a scale of $0-4$, with increments of 0.5. Equivalent to scoring for Pst, a score of 0 was symptomatic of no expression of the phenotype, i.e. no pustules observed, and a score of 4 was indicated full expression (i.e. $100 \%$ of the surface area covered in pustules).

Microscopic phenotyping. We adapted a protocol described by Ayliffe et al. ${ }^{91}$ that uses a stain that binds $\mathrm{N}$-acetyl-glucosamine (a major component of chitin) for the visualization of intercellular fungal growth. A detailed description of this protocol is made in Dawson et al. ${ }^{47}$. Briefly, leaves were harvest and placed in $1.0 \mathrm{M} \mathrm{KOH}$ ( $5 \mathrm{~mL}$ of $\mathrm{KOH}$ per barley leaf) with a droplet of surfactant (Silwet L-77, Loveland Industries Ltd.). The leaf tissue was incubated in $\mathrm{KOH}$ solution at $37^{\circ} \mathrm{C}$ between 12 and $16 \mathrm{~h}$ and then washed three times in $50 \mathrm{mM}$ Tris $\mathrm{pH}$ 7.5. After decanting of the wash solution, a $1.0 \mathrm{~mL}$ stain solution consisting of $20 \mu \mathrm{g} / \mathrm{mL}$ wheat germ agglutinin conjugated with FITC (L4895-10MG; Sigma-Aldrich) in $50 \mathrm{mM}$ Tris pH 7.5 was applied to leaf tissue and incubated overnight. Leaf tissue was then washed with water, mounted, and observed under blue light excitation using a mercury lamp with GFP filter in an AxioPhot fluorescence microscope (Zeiss) to visualize WGA-FITC-stained Pst. We developed a microscopy-based phenotypic assay to evaluate stripe rust reaction as percent colonization (pCOL), this was achieved by evaluating disjoint fields of view (FOV) covering the surface area of the leaf. Within each FOV, colonization of Pst was determined to be $<15 \%, 15-50 \%$ or $>50 \%$ and given scores of $0,0.5$, or 1 , respectively. The final pCOL score was determined by averaging these scores based on an entire leaf.

Genotyping. CAPS and SSLP markers were generated based on several known SNP-based markers (Supplementary Data 8) or existing report ${ }^{92}$. Markers were developed using barley oligo pooled assay markers ${ }^{48,93}$, SNPs derived from sequence variation in the Mla contig from barley cv. Morex ${ }^{30,57}$, and from previously characterized genotype by sequencing markers ${ }^{94,95}$. KASP genotyping was performed at the John Innes Centre genotyping facility (Supplementary Data 9). Oligonucleotide assay (OPA) and Sequenom genotyping was carried out as described by Dawson et al. ${ }^{55}$. OPA genotyping was performed at the University of California, Los Angeles Southern California Genotyping Consortium (Los Angeles, CA, USA) using 1,536 SNP-based markers (BOPA1) ${ }^{48}$. All Sequenom genotyping was performed by the Iowa State University Genomic Technologies Facility (Ames, IA, USA). CAPS marker reactions were performed using $2 \mu \mathrm{L}$ buffer $(10 \times), 0.4 \mu \mathrm{L}$ 
dNTPs, $0.4 \mu \mathrm{L}$ forward primer, $0.4 \mu \mathrm{L}$ reverse primer, $0.2 \mu \mathrm{L}$ Taq polymerase, $2 \mu \mathrm{L}$ gDNA at $10 \mathrm{ng} / \mu \mathrm{L}$, and $14.6 \mu \mathrm{L}$ water. PCR cycles involved initial denaturation step at $94^{\circ} \mathrm{C}$ for $5 \mathrm{~min}$, then $35 \mathrm{cycles}$ of $94^{\circ} \mathrm{C}$ for $20 \mathrm{~s}$, annealing at $56^{\circ} \mathrm{C}$ for $30 \mathrm{~s}$ and primer extension at $72{ }^{\circ} \mathrm{C}$ for $1 \mathrm{~min}$. A final extension at $72^{\circ} \mathrm{C}$ for $5 \mathrm{~min}$ before being held at $16^{\circ} \mathrm{C}$. Manufacturer's instructions were used for all restriction enzyme digestions. Electrophoresis was performed using $2.0 \%$ TBE agarose gels stained with ethidium bromide. Imaging was performed using a Bio-Rad ChemDoc XRS + imaging system and markers were visually assessed. For Sequenom marker development, SNP sequences were extracted in IUPAC format with 40-60 bp flanking sequence (Supplementary Data 10) and used as a template for primer design using MassARRAY software v3.1 for the multiplexing up to 32 SNP assays. Genetic maps were constructed based on the barley consensus genetic map ${ }^{93}$ and validated using $\mathrm{R} / \mathrm{qtl}$ recombination fraction plots ${ }^{96}$.

QTL and marker-trait association analysis. For populations with comprehensive genetic maps, composite interval mapping was performed using QTL Cartographer version $1.17 \mathrm{e}^{97,98}$ using a walking speed of $2 \mathrm{cM}$, a window size of $10 \mathrm{cM}$, and a maximum of five background parameters. Background parameters were selected using the FB method with default settings $\left(p\left(F_{\text {in }}\right)=p\left(F_{\text {out }}\right)=0.1\right)$. For each trait, the experiment-wise threshold (EWT) was determined using 1000 permutations with reselection of background parameters ${ }^{99}$. We automated QTL analysis and figure generation in the QKcartographer suite of Python scripts that are maintained on GitHub (https://github.com/matthewmoscou/QKcartographer). For populations with markers near $R p s 6, R p s 7$, and $R p s 8$, initial marker-trait regression was performed using a three additive QTL model including all loci. The model was then reduced based on a minimum threshold of $p=0.05$. Marker-trait association were evaluated for significance using 1000 permutations. Percent of variation explained (PVE) was estimated using R/qtl fitqtl with all significant QTLs under an additive model.

Recombination screens. Two recombination screens were performed using $\mathrm{F}_{2}$ progeny derived from the crosses CIho $4196 \times$ Morex and CI $16153 \times$ Manchuria. In both screens, recombinant individuals were selected using the flanking markers K_963924 and K_206D11. Informative markers for each population were applied to all recombinants derived from the recombination screens. A minimum of sixteen individuals from $\mathrm{F}_{2: 3}$ families were independently assessed using Pst isolate 08/ 21 for both populations and B. graminis f. sp. hordei isolate CC148 for the CI 16153 $\times$ Manchuria $\mathrm{F}_{2: 3}$ families

\section{Transcriptome sequencing and assembly. Transcriptome sequencing and} assembly was carried out according to Brabham et al..$^{32}$. Briefly, total RNA was extracted using a Trizol-phenol based protocol according to manufacturer's protocol (Sigma-Aldrich; T9424). Barcoded Illumina TruSeq RNA HT libraries were constructed and pooled with four samples per lane on a single HiSeq 2500 lane run in Rapid Run mode. Sequencing was performed using 150 bp paired-end reads. Paired-end reads were assessed for quality using FastQC and trimmed before assembly using Trimmomatic (v0.32) with parameters set at ILLUMINACLIP:2:30:10, LEADING:3, TRAILING:3, SLIDINGWINDOW:4:15, and MINLEN:100. These parameters were used to remove all reads with adapter sequence, ambiguous bases, or a substantial reduction in read quality. De novo transcriptome assemblies were generated using Trinity with default parameters (version 2013-1110) ${ }^{100}$. Alignments to RNAseq assemblies and controls were performed using bowtie2 (version 2.3.4.1) using default parameters.

Sequence capture and PacBio SMRT sequencing. Sequence capture and PacBio SMRT sequencing of NLR encoding genes (RenSeq) were carried out according to Witek et al. ${ }^{101}$. Briefly, gDNA extracted using a CTAB method, normalized to $3 \mu \mathrm{g}$, and sheared with a Covaris S2 sonicator (settings Duty Cycle 20\%, Intensity 1, Cycle Burst 1000, Time $600 \mathrm{~s}$, Sample volume $200 \mu \mathrm{L}$ ) to an average length of 3 to $4 \mathrm{~kb}$. Sequencing libraries were prepared using the NEBNext Ultra DNA Library Prep Kit for Illumina (NEB, MA, USA) using DNA fragments greater than $2 \mathrm{~kb}$ using Agencourt AMPure XP beads. Capturing NLR gene fragments was performed using a custom MYcroarray MYbaits bait library based on the barley resistance gene space (TSLMMHV1).

After ligation of Illumina sequencing adapters, the sample was purified with AMPure XP beads, and the subjected to eight cycles of PCR amplification using indexed PCR primers (NEBNext Multiplex Oligos for Illumina, New England Biolabs) and the Illumina PE1.0 PCR primer. The Bioanalyzer DNA 1000 chip (Agilent) was used for quality assays and the average fragment sizes and concentrations determined with a Qubit dsDNA assay. Approximately $500 \mathrm{ng}$ of the prepped library was hybridized in hybridization buffer (10x SSPE, 10X Denhardt's solution, $10 \mathrm{mM}$ EDTA, $0.2 \%$ SDS) to the biotinylated RNA baits for $20 \mathrm{~h}$ at $65^{\circ} \mathrm{C}$ on a thermocycler. Recovery of DNA using magnetic streptavidincoated beads was performed by adding $30 \mu \mathrm{L}$ Dynabeads MyOne Streptavidin C1 (Invitrogen, Life Technologies) that had been washed three times and resuspended in binding buffer ( $1 \mathrm{M} \mathrm{NaCl} ; 10 \mathrm{mM}$ Tris- $\mathrm{HCl}, \mathrm{pH} 7.5 ; 1 \mathrm{mM}$ EDTA). After $30 \mathrm{~min}$ at $65^{\circ} \mathrm{C}$, beads were pulled down and washed three times at $65^{\circ} \mathrm{C}$ for $10 \mathrm{~min}$ with $0.02 \% \mathrm{SSC} / 0.1 \%$ SDS followed by resuspension in $30 \mu \mathrm{L}$ of nuclease-free water. PCR amplification using Kapa HiFi HotStart Ready Mix (Kapa Biosystems) and Illumina P5 and P7 primers was performed with 26 cycles. Size fractionation of the amplified library was performed using a Sage Scientific Electrophoretic Lateral Fractionator (SageELF, Sage Science) using a 0.75\% SageELF agarose gel cassette. The fractions that ranged between 3 and $4 \mathrm{~kb}$ were pooled and purified with AMPure PB beads (Pacific Biosciences). SMRTbell Template Prep Kit 1.0 (Pacific Biosciences) was used to assemble the library according the 2-kb Template Preparation and Sequencing protocol (www.pacificbiosciences.com/support/ pubmap/documentation.html). PacBio RSII sequencing using C4-P6 chemistry was performed at the Earlham Institute (Norwich, UK), using four SMRT cells for each barley accession.

The complete design process of the library is described in Brabham et al. ${ }^{32}$. Briefly, the capture design TSLMMHV1 includes 99,421 100 mer baits that target the barley NLR gene space based on available genomic resources as well as the entire Mla interval, excluding repetitive sequence. This includes allelic variation in $R G H 1, R G H 2$, and $R G H 3$ gene families. In general, a target of $2 \mathrm{x}$ non-redundant coverage was achieved for all NLRs identified in the genomes of the barley accessions Barke, Bowman, and Morex, the full length cDNA from barley accession Haruna Nijo, and transcriptomes of barley accessions Abed Binder 12, Baronesse, CI 16153, CIho 4196, Manchuria, Pallas, Russell, and SusPtrit.

Preprocessing of PacBio circular consensus reads involved selecting only those reads with three or more passes, trimming of reads included the first first and last $70 \mathrm{bp}$, and size selected to reads less than $4 \mathrm{~kb}$. De novo assembly of PacBio circular consensus sequences was performed using Geneious (v10.2.3) using custom sensitivity parameters for assembly: don't merge variants with coverage over approximately 6 , merge homopolymer variants, allow gaps up to a maximum of $15 \%$ gaps per read, word length of 14 , minimum overlap of $250 \mathrm{bp}$, ignore words repeated more than 200 times, 5\% maximum mismatches per read, maximum gap size of 2 , minimum overlap identity of $90 \%$, index word length 12 , reanalyze threshold of 8 , and maximum ambiguity of 4 .

Phylogenetic tree construction. The barley reference gene space ${ }^{102}$ was used as template for performing alignments with bwa mem (version 0.7.5a-r405) using default parameters. Samtools (version 0.1.19-96b5f2294a) was used for file conversion and application of the requirement that reads mapped in a proper pair $(-\mathrm{f} 2)$. Reads were sorted and duplicate reads removed. Coverage of reads was determined using bedtools (version v2.17.0). SNPs and InDels were called using VarScan (version 2.3.8) with default parameters. The QKgenome suite (version 1.1.1) was used to assess allelic diversity in barley coding sequence among diverse genotypes ${ }^{80}$. The QKgenome_conversion.py script was used to assess nucleotide variation with read depth of equal to or greater than 20 across the entire coding sequence $^{80}$. A threshold of at least $90 \%$ was required for SNPs and InDels. All genes harboring InDels or mutations that disrupted the coding sequence (truncations) were excluded in the analysis. Multiple sequence alignment of polymorphic sites was performed using the QKgenome_phylogeny.py script (https:// github.com/matthewmoscou/QKphylogeny). Construction of the phylogenetic tree was performed with RAxML (version 8.2.9) using the GTRGAMMA nucleotide model and rapid hill-climbing mode. A total of 500 bootstraps were performed and sufficient based on the bootstrap convergence test.

Construct development and plant transformation. The open reading frames of Mla 8 and Mla6, and the promoter, UTRs, and terminator regions of Mla6 were amplified from barley accessions Haruna Nijo (Mlas) and CI 16151 (Mla6) ${ }^{103}$, respectively, using GoTaq Long PCR Master Mix (Promega). PCR bands were gel purified and cloned into pGem-T Easy vector (Promega) using 3:1 insert:vector molar ratios. Plasmid DNA from colonies were isolated and inserts were verified by Sanger sequencing. Mla1 is identical to Mla8 except for a $3^{\prime}$ region of $495 \mathrm{bp}(2,383$ to $2,877 \mathrm{bp}$ ). A template of $759 \mathrm{bp}$ fragment encompassing this region was synthesized by IDT based on the genomic sequence of Mla1 (NCBI AY009938 [https:// www.ncbi.nlm.nih.gov/nuccore/AY009938.2/]). Assembly of the correct fragments into pBract202 binary vector (BRACT) was performed by Gibson reaction ${ }^{104}$. PCR fragments bearing $20 \mathrm{bp}$ overlapping to the flanking region were produced with Phusion High-Fidelity DNA Polymerase (NEB) and 40-mer primers (Supplementary Data 11). After gel purification fragments were combined in an equimolar ratio, with a total DNA input of $200 \mathrm{ng}$ in a $5 \mu \mathrm{L}$ total volume. The mixture was added to $15 \mu \mathrm{L}$ of Gibson assembly master reaction and incubated for $1 \mathrm{hr}$ at $50{ }^{\circ} \mathrm{C}$. After incubation, $10 \mu \mathrm{L}$ of the assembly mix were transformed into chemically competent DH5a E. coli cells. The Gibson assembly master reaction was prepared by mixing $699 \mu \mathrm{L}$ water, $320 \mu \mathrm{L} 5 \mathrm{x}$ ISO buffer $(500 \mathrm{mM}$ Tris-HCl, pH 7.5, $250 \mathrm{mg} /$ mL PEG-8000, $50 \mathrm{mM} \mathrm{MgCl} 2,50 \mathrm{mM}$ DTT, $1 \mathrm{mM}$ dNTPs, $5 \mathrm{mM}$ NAD), $0.64 \mu \mathrm{L}$ T5 exonuclease (NEB, $10 \mathrm{U} / \mu \mathrm{L}), 20 \mu \mathrm{L}$ Phusion DNA polymerase (NEB, $2 \mathrm{U} / \mu \mathrm{L})$ and $160 \mu \mathrm{L}$ Taq DNA ligase (NEB, $40 \mathrm{U} / \mu \mathrm{L}$ ). Plasmid DNA was isolated from colonies and assessed by restriction digestion to verify the assembly of all the fragments. Integrity and sequence of positive clones were confirmed using Sanger sequencing. Transformation of the wheat stripe rust susceptible SusPtrit $\times$ Golden Promise DH-47 from the SxGP doubled-haploid population ${ }^{53}$ was performed by using the technique described by Hensel et al. ${ }^{105}$ using the hygromycin resistance gene $(h y g)$ as a selectable marker.

Copy number variation. Fresh leaves of plants were harvested and freeze-dried for $48 \mathrm{~h}$ prior to genomic DNA extraction using a CTAB-based protocol. DNA 
concentrations were measured using Qubit dsDNA assay. Droplet-Digital PCR (ddPCR) was used for detection of copy number. Primers for ddPCR include Actin (AK365182) for normalization: forward $5^{\prime}$-TTTGGTGCTAGCGTGGGG-3' ${ }^{\prime}$ and reverse 5'-AGCAAGTACTAGGGGCCGA-3', Mla8: forward 5'-GCCGTGTATAG CAGAAGGTG- $3^{\prime}$ and reverse $5^{\prime}$-CTGCTACATACCTCGAGAGCA- $3^{\prime}$, and Mla 7 forward $5^{\prime}$-TCTGGCCATGCAGAAGCC- $3^{\prime}$ reverse $5^{\prime}$-CCAGACACGAGCAACC GT- $3^{\prime}$. The Mla7 primers are identical to Mla13 (CI 161555) and RGH1 in SusPtrit and were used for amplification of these genes. PCR reactions contained $10 \mu \mathrm{L}$ of QX200 ddPCR EvaGreen Supermix (Bio-Rad Laboratories), $100 \mathrm{nM}$ of each primer, $15 \mathrm{ng}$ of genomic DNA, 4 units of HindIII restriction enzyme, and distilled water to a volume of $20 \mu \mathrm{L}$. PCR mixtures were separated into droplets by a BioRad QX200 Droplet Generator. PCR amplification was performed in a Bio-Rad C1000 Thermal Cycler with the following PCR conditions: $95^{\circ} \mathrm{C}$ for $7 \mathrm{~min}, 40$ cycles of $30 \mathrm{~s}$ at $94^{\circ} \mathrm{C}, 30 \mathrm{~s}$ at $58^{\circ} \mathrm{C}$ and $60 \mathrm{~s}$ at $72^{\circ} \mathrm{C}$, followed by signal stabilization steps at $4{ }^{\circ} \mathrm{C}$ for $5 \mathrm{~min}$ and $90^{\circ} \mathrm{C}$ for $5 \mathrm{~min}$. After PCR amplification droplets were analyzed using a Bio-Rad QX200 Droplet Reader with Bio-Rad QuantaSoft software version 1.4. The ratio of positive to total droplets of the target gene was normalized to actin. Three biological replicates were used by independently extracting gDNA from different plants. Copy number variation in transgenic plants carrying Mla1, Mla6, and Mla8 was determined by iDna Genetics (Norwich, UK) by quantitative real time PCR using the selectable marker gene hyg similar to the approach by Bartlett et al. ${ }^{106}$.

Reporting summary. Further information on research design is available in the Nature Research Reporting Summary linked to this article.

\section{Data availability}

The RNAseq data generated in this study have been deposited in the NCBI database under BioProject accessions PRJNA292371, PRJNA376252, PRJNA378334, and PRJNA378723. The NLR gene captures of barley accessions CI 16153 and Golden Promise generated in this study have been deposited in the NCBI database under BioProject accessions PRJNA523805 and PRJNA523807, respectively. The sequences of plasmids used for plant transformation are available in the source data file for Supplementary Fig. 3, and Figshare ${ }^{107}$. Genotypic, phenotypic, and raw data for figures and supplementary figures have been deposited on Figshare ${ }^{107,108}$. A material transfer agreement with The Sainsbury Laboratory is required to receive any materials. The use of the materials will be limited to non-commercial research uses only. Please contact M.J.M. (matthew.moscou@tsl.ac.uk) regarding the transgenic materials, and requests will be responded within 60 days. Source data are provided with this paper.

\section{Code availability}

The QKcartographer, QKgenome, and QKphylogeny suite of Python scripts are maintained on GitHub [https://github.com/matthewmoscou/QKcartographer; https:// github.com/matthewmoscou/QKgenome; https://github.com/matthewmoscou/ QKphylogeny] and Figshare ${ }^{107,109-111}$.

Received: 9 May 2019; Accepted: 11 November 2021; Published online: 25 November 2021

\section{References}

1. Panstruga, R. \& Moscou, M. J. What is the molecular basis of nonhost resistance? Mol. Plant-Microbe Interact. 33, 1253-1264 (2020).

2. Heath, M. C. A comparative study of non-host interactions with rust fungi. Physiol. Plant Pathol. 10, 73-88 (1977).

3. Eriksson, J. Ueber die Specialisirung des Parasitismus bei den Getreiderostpilzen. Berichte der Deutschen Botanischen Gesellschaft 12 (1894).

4. Marchal, É. De la spécialisation du parasitisme chez l'Erysiphe graminis. Comptes Rendus Hebdomadaires des Séances de l'Académie des Sciences CXXXV, 210-212 (1902).

5. Nielsen, J. Host range of the smut species Ustilago nuda and Ustilago tritici in the tribe Triticeae. Can. J. Bot. /Rev. Can. Bot. 56, 901-915 (1978).

6. Edel-Hermann, V. \& Lecomte, C. Current status of Fusarium oxysporum formae speciales and races. Phytopathology 109, 512-530 (2019).

7. Kato, H. Biological and genetical aspects in the perfect state of rice blast fungus Pyricularia oryzae Cav. and its allies. In: Gamma Field Symposia No. 17. Mutation Breeding for Disease Resistance, 1-22 (1978).

8. Crute, I. in The Downy Mildews (ed Spenser, D. M.) 237-255 (Academic Press, 1981).

9. Saharan, G. S. \& Verma, P. R. White Rusts: a Review of Economically Important Species (International Development Research Centre, 1992).

10. Riley, R. \& Macer, R. C. F. The chromosomal distribution of the genetic resistance of rye to wheat pathogens. Can. J. Genet. Cytol. 8, 640-653 (1966).
11. Tosa, Y. Genetic analysis of the avirulence of wheatgrass powdery mildew fungus on common wheat. Genome 32, 913-917 (1989).

12. Thordal-Christensen, H. Fresh insights into processes of nonhost resistance. Curr. Opin. Plant Biol. 6, 351-357 (2003).

13. Jones, J. D. \& Dangl, J. L. The plant immune system. Nature 444, 323-329 (2006).

14. Boller, T. \& Felix, G. A renaissance of elicitors: perception of microbeassociated molecular patterns and danger signals by pattern-recognition receptors. Annu. Rev. Plant Biol. 60, 379-406 (2009).

15. Boutrot, F. \& Zipfel, C. Function, discovery, and exploitation of plant pattern recognition receptors for broad-spectrum disease resistance. Annu. Rev. Phytopathol. 55, 257-286 (2017).

16. Jacob, F., Vernaldi, S. \& Maekawa, T. Evolution and conservation of plant NLR functions. Front. Immunol. 4, 297 (2013).

17. Wilson, R. A. \& Talbot, N. J. Under pressure: investigating the biology of plant infection by Magnaporthe oryzae. Nat. Rev. Microbiol. 7, 185-195 (2009).

18. de Jonge, R. et al. Conserved fungal LysM effector Ecp6 prevents chitintriggered immunity in plants. Science 329, 953-955 (2010).

19. Toruno, T. Y., Stergiopoulos, I. \& Coaker, G. Plant-pathogen effectors: cellular probes interfering with plant defenses in spatial and temporal Manners. Annu. Rev. Phytopathol. 54, 419-441 (2016).

20. Michelmore, R. W. \& Meyers, B. C. Clusters of resistance genes in plants evolve by divergent selection and a birth-and-death process. Genome Res. $\mathbf{8}$, 1113-1130 (1998)

21. Dodds, P. N. \& Rathjen, J. P. Plant immunity: towards an integrated view of plant-pathogen interactions. Nat. Rev. Genet. 11, 539-548 (2010).

22. Gassmann, W., Hinsch, M. E. \& Staskawicz, B. J. The Arabidopsis RPS4 bacterial-resistance gene is a member of the TIR-NBS-LRR family of diseaseresistance genes. Plant J. 20, 265-277 (1999).

23. Deslandes, L. et al. Physical interaction between RRS1-R, a protein conferring resistance to bacterial wilt, and PopP2, a type III effector targeted to the plant nucleus. Proc. Natl Acad. Sci. USA 100, 8024-8029 (2003).

24. Narusaka, M. et al. RRS1 and RPS4 provide a dual Resistance-gene system against fungal and bacterial pathogens. Plant J. 60, 218-226 (2009).

25. Birker, D. et al. A locus conferring resistance to Colletotrichum higginsianum is shared by four geographically distinct Arabidopsis accessions. Plant J. 60, 602-613 (2009).

26. Nombela, G., Williamson, V. M. \& Muniz, M. The root-knot nematode resistance gene $\mathrm{Mi}-1.2$ of tomato is responsible for resistance against the whitefly Bemisia tabaci. Mol. Plant-Microbe Interact. 16, 645-649 (2003).

27. Atamian, H. S., Eulgem, T. \& Kaloshian, I. SIWRKY70 is required for Mi-1mediated resistance to aphids and nematodes in tomato. Planta 235, 299-309 (2012).

28. Briggs, F. N. \& Stanford, E. H. Linkage of factors for resistance to mildew in barley. J. Genet. 37, 107-117 (1938).

29. Zhou, F. et al. Cell-autonomous expression of barley Mla1 confers racespecific resistance to the powdery mildew fungus via a Rar1-independent signaling pathway. Plant Cell 13, 337-350 (2001).

30. Wei, F., Wing, R. A. \& Wise, R. P. Genome dynamics and evolution of the Mla (powdery mildew) resistance locus in barley. Plant Cell 14, 1903-1917 (2002).

31. Seeholzer, S. et al. Diversity at the Mla powdery mildew resistance locus from cultivated barley reveals sites of positive selection. Mol. Plant-Microbe Interact. 23, 497-509 (2010)

32. Brabham, H. J., Hernández-Pinzón, I., Holden, S., Lorang, J. \& Moscou, M. J. An ancient integration in a plant NLR is maintained as a trans-species polymorphism. bioRxiv https://doi.org/10.1101/239541 (2018).

33. Jørgensen, J. H. Genetics of powdery mildew resistance in barley. Crit. Rev. Plant Sci. 13, 97-119 (1994).

34. Kinizios, S., Jahoor, A. \& Fischbeck, G. Powdery-mildew-resistance genes Mla29 and Mla32 in H. spontaneum derived winter-barley lines. Plant Breed. /Z. Pflanzenzucht 114, 265-266 (1995).

35. Periyannan, S. et al. The gene Sr33, an ortholog of barley Mla genes, encodes resistance to wheat stem rust race Ug99. Science 341, 786-788 (2013).

36. Jordan, T. et al. The wheat Mla homologue TmMlal exhibits an evolutionarily conserved function against powdery mildew in both wheat and barley. Plant $J$. 65, 610-621 (2011).

37. Mago, R. et al. The wheat Sr50 gene reveals rich diversity at a cereal disease resistance locus. Nat. Plants 1, 15186 (2015).

38. Lu, X. et al. Allelic barley MLA immune receptors recognize sequenceunrelated avirulence effectors of the powdery mildew pathogen. Proc. Natl Acad. Sci. USA 113, E6486-E6495 (2016).

39. Chen, J. et al. Loss of AvrSr50 by somatic exchange in stem rust leads to virulence for Sr50 resistance in wheat. Science 358, 1607 (2017).

40. Saur, I. M. et al. Multiple pairs of allelic MLA immune receptor-powdery mildew AVRA effectors argue for a direct recognition mechanism. eLife $\mathbf{8}$, e44471 (2019)

41. Savary, S. et al. The global burden of pathogens and pests on major food crops. Nat. Ecol. Evolution 3, 430-439 (2019). 
42. Derevnina, L., Zhou, M., Singh, D., Wellings, C. R. \& Park, R. F. The genetic basis of resistance to barley grass yellow rust (Puccinia striiformis $\mathrm{f}$. $\mathrm{sp}$. pseudo-hordei) in Australian barley cultivars. Theor. Appl. Genet. 128, 187-197 (2015).

43. Dracatos, P. M., Haghdoust, R., Singh, D. \& Park, R. F. Exploring and exploiting the boundaries of host specificity using the cereal rust and mildew models. N. Phytol. 218, 453-462 (2018).

44. Haghdoust, R., Singh, D., Garnica, D. P., Park, R. F. \& Dracatos, P. M. Isolate specificity and polygenic inheritance of resistance in barley to diverse heterologous Puccinia striiformis isolates. Phytopathology 108, 617-626 (2018).

45. Niks, R. E., Alemu, S. K., Marcel, T. C. \& van Heyzen, S. Mapping genes in barley for resistance to Puccinia coronata from couch grass and to P. striiformis from brome, wheat and barley. Euphytica 206, 487-499 (2015).

46. Straib, W. Untersuchungen über das Vorkommen physiologischer Rassen des Gelbrostes (Puccinia glumarum) in den Jaren 1935/36 und über die Aggressivität einiger neuer Formen auf Getreide und Gräsern. Arb. biol. Abt. (Anst. -Reichsanst.), Berl. 22, 91-119 (1937).

47. Dawson, A. M. et al. The development of quick, robust, quantitative phenotypic assays for describing the host-nonhost landscape to stripe rust. Front. Plant Sci. 6, 876 (2015).

48. Close, T. J. et al. Development and implementation of high-throughput SNP genotyping in barley. BMC Genomics 10, 582 (2009).

49. Hovmøller, M. S., Sørensen, C. K., Walter, S. \& Justesen, A. F. Diversity of Puccinia striiformis on cereals and grasses. Annu. Rev. Phytopathol. 49, 197-217 (2011).

50. Thomas, W. et al. HGCA Project Report 528: Association Genetics of UK Elite Barley (AGOUEB) (Agriculture and Horticulture Development Board, 2014).

51. Steffenson, B. J. et al. A walk on the wild side: mining wild wheat and barley collections for rust resistance genes. Aust. J. Agric. Res. 58, 532-544 (2007).

52. Atienza, S. G., Jafary, H. \& Niks, R. E. Accumulation of genes for susceptibility to rust fungi for which barley is nearly a nonhost results in two barley lines with extreme multiple susceptibility. Planta 220, 71-79 (2004).

53. Yeo, F. K. et al. Golden SusPtrit: a genetically well transformable barley line for studies on the resistance to rust fungi. Theor. Appl. Genet. 127, 325-337 (2014).

54. Li, K. et al. Fine mapping of barley locus Rps6 conferring resistance to wheat stripe rust. Theor. Appl. Genet. 129, 845-859 (2016).

55. Dawson, A. M. et al. Isolation and fine mapping of Rps6: an intermediate host resistance gene in barley to wheat stripe rust. Theor. Appl. Genet. 129, 831-843 (2016).

56. Büschges, R. et al. The barley Mlo gene: a novel control element of plant pathogen resistance. Cell 88, 695-705 (1997).

57. Wei, F. et al. The Mla (powdery mildew) resistance cluster is associated with three NBS-LRR gene families and suppressed recombination within a $240-\mathrm{kb}$ DNA interval on chromosome 5S (1HS) of barley. Genetics 153, 1929-1948 (1999).

58. Moseman, J. G. Isogenic barley lines for reaction to Erysiphe graminis f. sp. hordei. Crop Sci. 12, 681-682 (1972).

59. Kølster, P., Munk, L., Stølen, O. \& Løhde, J. Near-isogenic barley lines with genes for resistance to powdery mildew. Crop Sci. 26, 903-907 (1986).

60. Kølster, P. \& Stølen, O. Barley isolines with genes for resistance to Erysiphe graminis f. sp. hordei in the recurrent parent 'Siri'. Plant Breed. /Z. Pflanzenzucht 98, 79-82 (1987).

61. Maekawa, T. et al. Subfamily-specific specialization of RGH1/MLA immune receptors in wild barley. Mol. Plant-Microbe Interact. 32, 107-119 (2019).

62. Halterman, D. A. \& Wise, R. P. A single-amino acid substitution in the sixth leucine-rich repeat of barley MLA6 and MLA13 alleviates dependence on RAR1 for disease resistance signaling. Plant J. 38, 215-226 (2004).

63. Schreiber, M. et al. A genome assembly of the barley 'Transformation Reference' cultivar Golden Promise. G3 (Bethesda) 10, 1823-1827 (2020).

64. Bauer, S. et al. The leucine-rich repeats in allelic barley MLA immune receptors define specificity towards sequence-unrelated powdery mildew avirulence effectors with a predicted common RNase-like fold. PLoS Path. 17, e1009223 (2021).

65. Inukai, T., Vales, M. I., Hori, K., Sato, K. \& Hayes, P. M. RMol confers blast resistance in barley and is located within the complex of resistance genes containing Mla, a powdery mildew resistance gene. Mol. Plant-Microbe Interact. 19, 1034-1041 (2006).

66. Leng, Y. et al. The gene conferring susceptibility to spot blotch caused by Cochliobolus sativus is located at the Mla locus in barley cultivar Bowman. Theor. Appl. Genet. 131, 1531-1539 (2018).

67. Wiesner-Hanks, T. \& Nelson, R. Multiple disease resistance in plants. Annu. Rev. Phytopathol. 54, 229-252 (2016).

68. Milligan, S. B. et al. The root knot nematode resistance gene Mi from tomato is a member of the leucine zipper, nucleotide binding, leucine-rich repeat family of plant genes. Plant Cell 10, 1307-1319 (1998).
69. Debieu, M., Huard-Chauveau, C., Genissel, A., Roux, F. \& Roby, D. Quantitative disease resistance to the bacterial pathogen Xanthomonas campestris involves an Arabidopsis immune receptor pair and a gene of unknown function. Mol. Plant Pathol. 17, 510-520 (2016).

70. Le Roux, C. et al. A receptor pair with an integrated decoy converts pathogen disabling of transcription factors to immunity. Cell 161, 1074-1088 (2015).

71. Sarris, P. F. et al. A plant immune receptor detects pathogen effectors that target WRKY transcription factors. Cell 161, 1089-1100 (2015).

72. Maekawa, T., Kracher, B., Vernaldi, S., Ver Loren van Themaat, E. \& SchulzeLefert, P. Conservation of NLR-triggered immunity across plant lineages. Proc. Natl Acad. Sci. USA 109, 20119-20123 (2012).

73. Ames, N., Dreiseitl, A., Steffenson, B. J. \& Muehlbauer, G. J. Mining wild barley for powdery mildew resistance. Plant Pathol. 64, 1396-1406 (2015)

74. Collard, B. C. \& Mackill, D. J. Marker-assisted selection: an approach for precision plant breeding in the twenty-first century. Philos. Trans. R. Soc. Lond. B: Biol. Sci. 363, 557-572 (2008).

75. Meehan, F. \& Murphy, H. C. A new Helminthosporium blight of oats. Science 104, 413-414 (1946).

76. Inoue, Y. et al. Evolution of the wheat blast fungus through functional losses in a host specificity determinant. Science 357, 80-83 (2017).

77. Ullrich, S. E. Barley, Production, Improvement, and Uses. Vol. 1 (WileyBlackwell, 2011).

78. Wellings, C. R. Puccinia striiformis in Australia: a review of the incursion, evolution, and adaptation of stripe rust in the period 1979-2006. Aust. J. Agric. Res. 58, 567-575 (2007).

79. Chen, X. M., Line, R. F. \& Leung, H. Virulence and polymorphic DNA relationships of Puccinia striiformis $\mathrm{f}$. sp. hordei to other rusts. Phytopathology 85, 1335-1342 (1995).

80. Bettgenhaeuser, J. et al. The genetic architecture of colonization resistance in Brachypodium distachyon to non-adapted stripe rust (Puccinia striiformis) isolates. PLoS Genet. 14, e1007637 (2018).

81. Hubbard, A. et al. Field pathogenomics reveals the emergence of a diverse wheat yellow rust population. Genome Biol. 16, 23 (2015).

82. Niks, R. E., van Heyzen, S., Szabo, L. J. \& Alemu, S. K. Host status of barley to Puccinia coronata from couch grass and P. striiformis from wheat and brome. Eur. J. Plant Pathol. 136, 393-405 (2013).

83. Brown, J. K. \& Tellier, A. Plant-parasite coevolution: bridging the gap between genetics and ecology. Annu. Rev. Phytopathol. 49, 345-367 (2011).

84. Horsley, R. D. et al. Identification of QTLs associated with Fusarium head blight resistance in barley accession CIho 4196. Crop Sci. 46, 145-156 (2006).

85. Sato, K., Nankaku, N. \& Takeda, K. A high-density transcript linkage map of barley derived from a single population. Heredity 103, 110-117 (2009).

86. Dreiseitl, A. A novel resistance against powdery mildew found in winter barley cultivars. Plant Breed. 138, 840-845 (2019).

87. Stewart, C. N. Jr \& Via, L. E. A rapid CTAB DNA isolation technique useful for RAPD fingerprinting and other PCR applications. BioTechniques 14, 748-750 (1993).

88. Dreiseitl, A. Pathogenic divergence of Central European and Australian populations of Blumeria graminis f. sp. hordei. Ann. Appl. Biol. 165, 364-372 (2014).

89. Torp, J., Jensen, H. P. \& Jørgensen, J. H. Powdery mildew resistance genes in 106 Northwest European spring barley cultivars. Kongelige Veterinaer- Og Landbohoejskole, 75-102 (1978).

90. McNeal, F. H., Konzak, C. F., Smith, E. P., Tate, W. S. \& Russell, T. S. A uniform system for recording and processing cereal research data. U. S. Dep. Agriculture-Agric. Res. Serv. ARS 34-121, 42 (1971).

91. Ayliffe, M. et al. Nonhost resistance of rice to rust pathogens. Mol. PlantMicrobe Interact. 24, 1143-1155 (2011).

92. Kota, R. et al. EST-derived single nucleotide polymorphism markers for assembling genetic and physical maps of the barley genome. Funct. Integr. Genomics 8, 223-233 (2008).

93. Muñoz-Amatriaín, M. et al. An improved consensus linkage map of barley based on flow-sorted chromosomes and single nucleotide polymorphism markers. Plant Genome 4, 238-249 (2011)

94. Mascher, M. et al. Anchoring and ordering NGS contig assemblies by population sequencing (POPSEQ). Plant J. 76, 718-727 (2013).

95. Poland, J. A., Brown, P. J., Sorrells, M. E. \& Jannink, J. L. Development of high-density genetic maps for barley and wheat using a novel two-enzyme genotyping-by-sequencing approach. PLoS ONE 7, e32253 (2012).

96. Broman, K. W., Wu, H., Sen, S. \& Churchill, G. A. R/qtl: QTL mapping in experimental crosses. Bioinformatics 19, 889-890 (2003).

97. Basten, C. J., Weir, B. S. \& Zeng, Z.-B. In: Proc. 5th World Congress on Genetics Applied to Livestock Production: Computing Strategies and Software (eds C. Smith et al.) 65-66 (Organizing Committee, 5th World Congress on Genetics Applied to Livestock Production, Guelph, Ontario, Canada).

98. Basten, C. J., Weir, B. S. \& Zeng, Z.-B. QTL Cartographer Version 1.16 (Department of Statistics, North Carolina State University, 2002). 
99. Lauter, N., Moscou, M. J., Habiger, J. \& Moose, S. P. Quantitative genetic dissection of shoot architecture traits in maize: towards a functional genomics approach. Plant. Genome 1, 99-110 (2008).

100. Grabherr, M. G. et al. Full-length transcriptome assembly from RNA-Seq data without a reference genome. Nat. Biotechnol. 29, 644-652 (2011).

101. Witek, K. et al. Accelerated cloning of a potato late blight-resistance gene using RenSeq and SMRT sequencing. Nat. Biotechnol. 34, 656-660 (2016).

102. IBGSC. A physical, genetic and functional sequence assembly of the barley genome. Nature 491, 711-716 (2012).

103. Halterman, D., Zhou, F., Wei, F., Wise, R. P. \& Schulze-Lefert, P. The MLA6 coiled-coil, NBS-LRR protein confers AvrMla6-dependent resistance specificity to Blumeria graminis f. sp. hordei in barley and wheat. Plant J. 25, 335-348 (2001).

104. Gibson, D. G. Programming biological operating systems: genome design, assembly and activation. Nat. Methods 11, 521 (2014).

105. Hensel, G., Kastner, C., Oleszczuk, S., Riechen, J. \& Kumlehn, J. Agrobacteriummediated gene transfer to cereal crop plants: Current protocols for barley, wheat, triticale, and maize. Int. J. Plant Genomics 2009, 9 (2009).

106. Bartlett, J. G., Alves, S. C., Smedley, M., Snape, J. W. \& Harwood, W. A. Highthroughput Agrobacterium-mediated barley transformation. Plant Methods 4, 22 (2008).

107. Moscou, M. J. Source data for all figures in the manuscript entitled 'The barley immune receptor Mla recognizes multiple pathogens and contr ibutes to host range dynamics'. Figshare, https://doi.org/10.6084/m9.figshare.16918774 (2021).

108. Moscou, M. J. Genotypic and phenotypic analysis of 31 barley populations inoculated with wheat stripe rust. Figshare, https://doi.org/10.6084/ m9.figshare.7763018.v1 (2021).

109. Moscou, M. J. QKcartographer: a set of scripts for processing QTL Cartographer output. Figshare, https://doi.org/10.6084/ m9.figshare.16912210.v1 (2021).

110. Moscou, M. J. QKdomain: a set of scripts that can be used for domain analysis. Figshare, https://doi.org/10.6084/m9.figshare.16923799 (2021).

111. Moscou, M. J. Q. Kgenome. A set of scripts for converting genomes based on resequencing information. Figshare, https://doi.org/10.6084/ m9.figshare.16923802 (2021).

\section{Acknowledgements}

The authors greatly appreciated valuable discussions with Peter van Esse, Jonathan Jones, Sophien Kamoun, Nick Talbot, and Cyril Zipfel. Photography was supported by Andrew Davis and Phil Robinson. Assistance in the greenhouse was provided by Sue Banfield and the John Innes Horticultural team. Seed was kindly provided by Andy Kleinhofs, Rients Niks, Ralph Panstruga, Mapi Valles, Wolfgang Spielmeyer, Nils Stein, Wendy Harwood, Wheat Genetics Resource Center (Kansas State University), Patrick Hayes, Kazuhiro Sato, Roger Wise, and the National Small Grains Collection (USDA-ARS). Funding for this research includes Biotechnology and Biological Sciences Research Council Doctoral Training Programme (grant no. BB/F017294/1 to J.B. and M.J.M.) and Institute Strategic
Programme (grant no. BB/J004553/1 to B.B.H.W., BB/P012574/1 to M.J.M., and BBS/E/ J/000PR9795 to M.J.M.), Human Frontier Science Program Long-term Fellowship (gran no. LT000218/2011-L to M.J.M.), John Innes Foundation (rotation PhD studentship to PE), 2Blades Foundation, and Gatsby Charitable Foundation.

\section{Author contributions}

Design of the research: J.B., I.H.P., A.M.D., R.B., B.B.H.W., A.D., E.R.W., and M.J.M.; performing the research: J.B., I.H.P., A.M.D., M.G., P.G., J.T., M.S., J.N.F., P.E., A.H., J.C., B.S., A.D., and M.J.M.; data analysis: J.B., I.H.P., A.M.D., M.S., R.W., A.D., and M.J.M.; manuscript writing: J.B., I.H.P., A.M.D., and M.J.M.

\section{Competing interests}

Patent application PCT/US2016/060101 filed by M.J.M. and A.M.D. that encompasses the map-based cloning and identification of the candidate gene for Rps6. The remaining authors declare no competing interests.

\section{Additional information}

Supplementary information The online version contains supplementary material available at https://doi.org/10.1038/s41467-021-27288-3.

Correspondence and requests for materials should be addressed to Matthew J. Moscou

Peer review information Nature Communications thanks Rients Niks, Paul SchulzeLefert and Hans Thordal-Christensen for their contribution to the peer review of this work. Peer reviewer reports are available.

Reprints and permission information is available at http://www.nature.com/reprints

Publisher's note Springer Nature remains neutral with regard to jurisdictional claims in published maps and institutional affiliations.

Open Access This article is licensed under a Creative Commons Attribution 4.0 International License, which permits use, sharing, adaptation, distribution and reproduction in any medium or format, as long as you give appropriate credit to the original author(s) and the source, provide a link to the Creative Commons license, and indicate if changes were made. The images or other third party material in this article are included in the article's Creative Commons license, unless indicated otherwise in a credit line to the material. If material is not included in the article's Creative Commons license and your intended use is not permitted by statutory regulation or exceeds the permitted use, you will need to obtain permission directly from the copyright holder. To view a copy of this license, visit http://creativecommons.org/ licenses/by/4.0/

(C) The Author(s) 202 